Supporting Information

\title{
Lithocholic Acid Derivatives as Potent Vitamin D Receptor Agonists
}

Harue Sasaki, Hiroyuki Masuno, Haru Kawasaki, Ayana Yoshihara, Nobutaka Numoto, Nobutoshi Ito, Hiroaki Ishida, Keiko Yamamoto, Naoya Hirata, Yasunari Kanda, Emiko Kawachi, Hiroyuki Kagechika,* Aya Tanatani*

\section{Content}

Figure S1. Comparison of ${ }^{1} \mathrm{H}$ NMR of compounds 14a and $14 \mathbf{b}$

Figure S2. Comparison of overall crystal structures of VDR-ligand complexes

Figure S3. ${ }^{1} \mathrm{H}$ and ${ }^{13} \mathrm{C}$ NMR charts of compounds 
Figure S1. Comparison of ${ }^{1} \mathrm{H}$ NMR of compounds 14a and 14b

Chemical structure, possible three-dimensional structure, and ${ }^{1} \mathrm{H}$ NMR signal of proton at 3 position of (a) 14a and (b) $14 b$ are shown.

(a) $14 a(3 \alpha)$

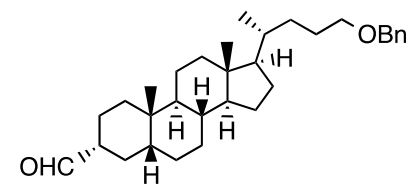

possible three-dimensional structure

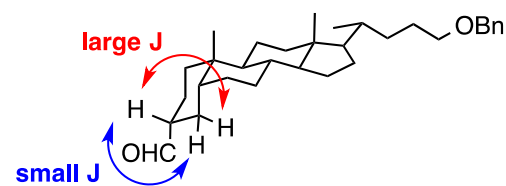

${ }^{1} \mathrm{H}$ NMR signal of proton at 3 position

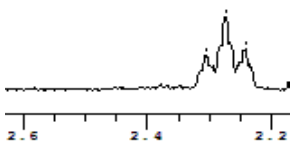

(a) $14 b(3 \beta)$
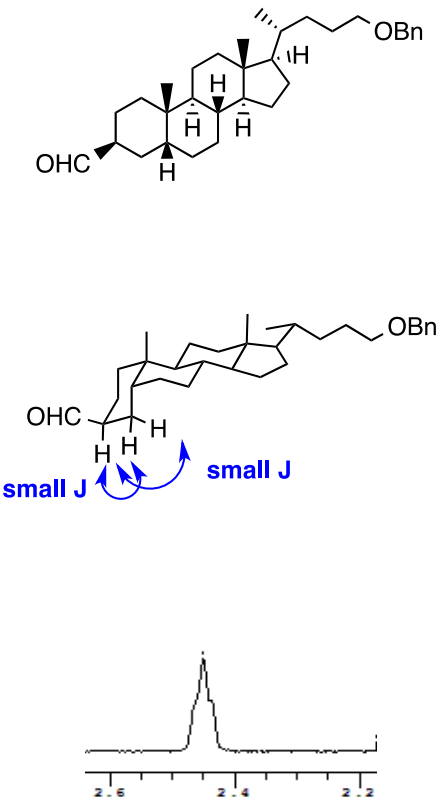
Figure S2. Comparison of overall crystal structures of VDR-ligand complexes. Coactivator was shown in red color.

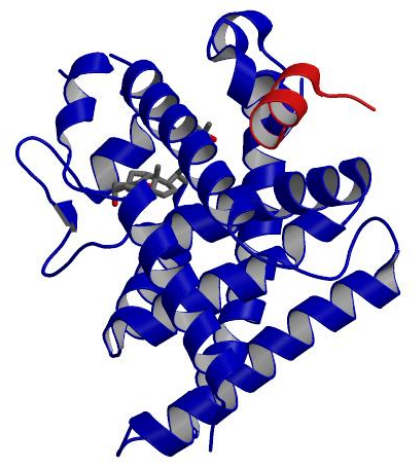

1 ,25-Dihydroxyvitamin $D_{3}(1)$

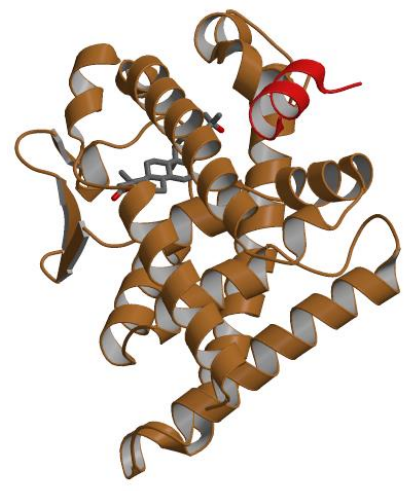

Compound 6

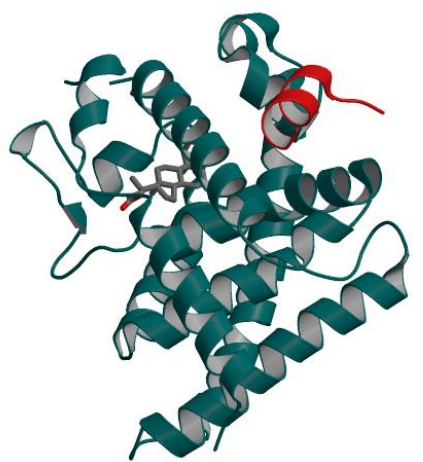

Lithocholic acid (2)

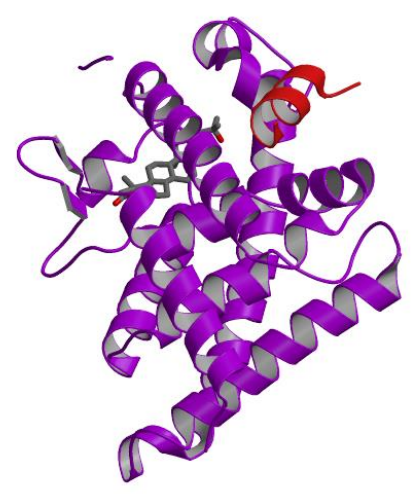

Compound 7 
Figure S3. ${ }^{1} \mathrm{H}$ and ${ }^{13} \mathrm{C}$ NMR charts of compounds

(i) compound 9

${ }^{1} \mathrm{H} \mathrm{NMR}$

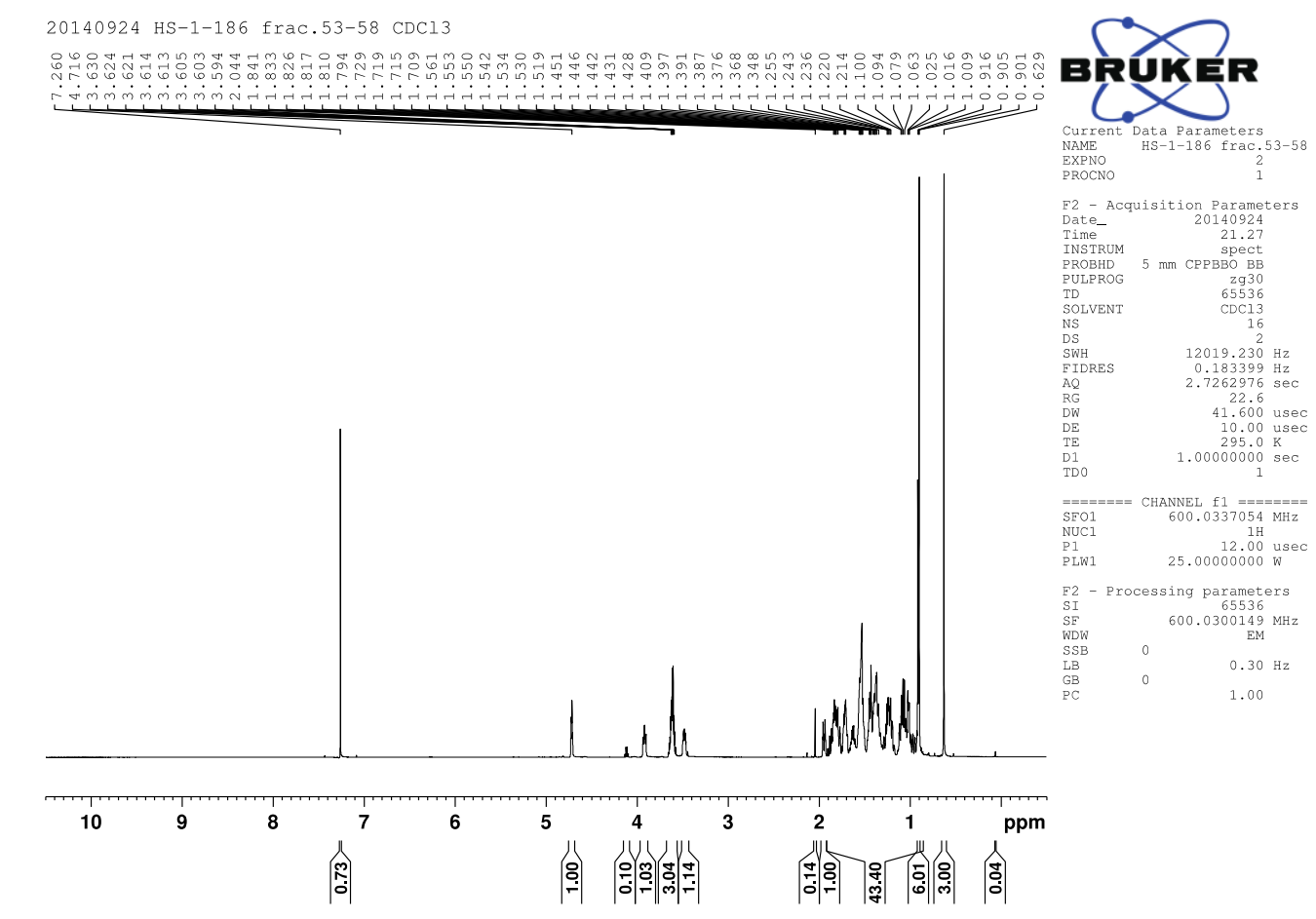

\section{${ }^{13} \mathrm{C}$ NMR}
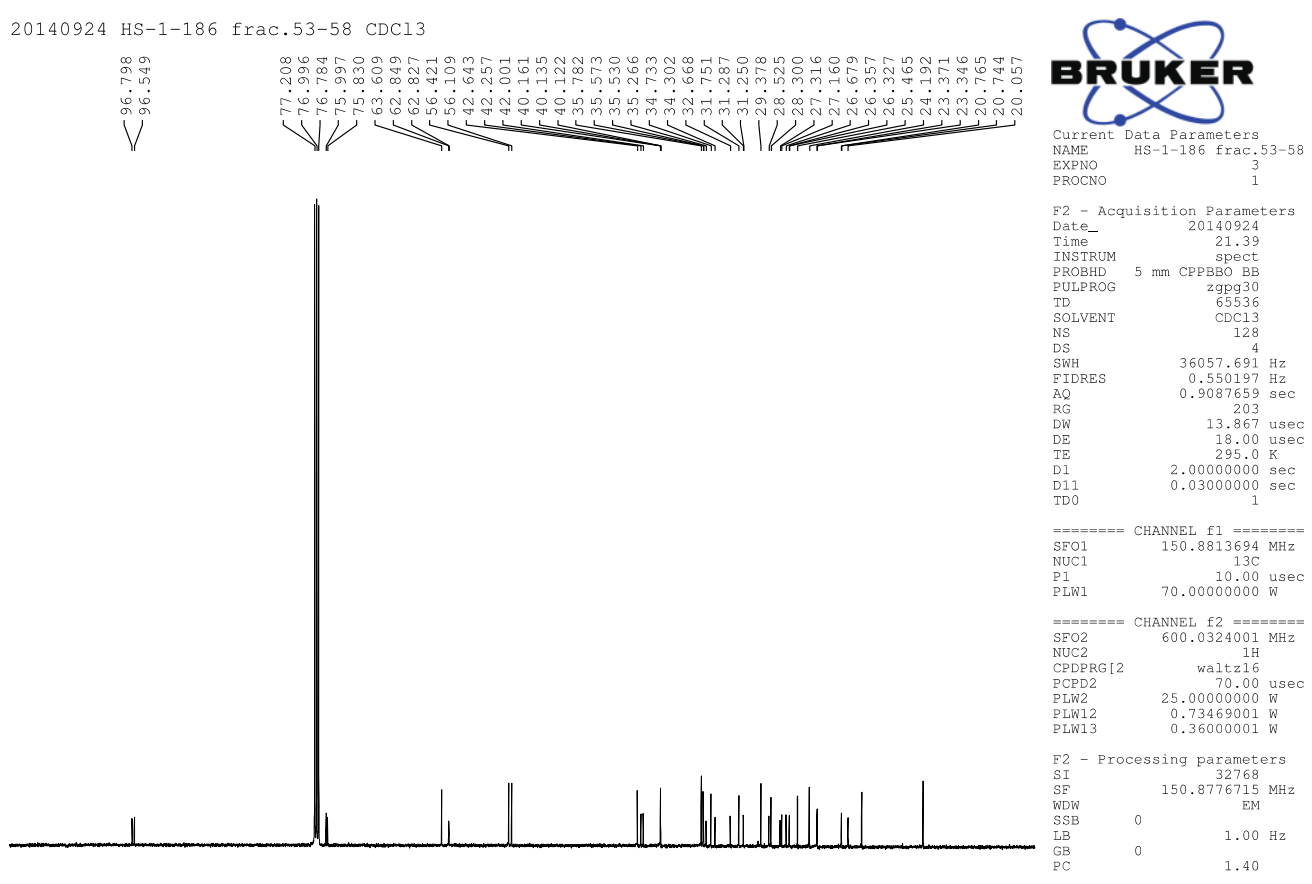
(ii) compound $\mathbf{1 0}$

${ }^{1} \mathrm{H}$ NMR

20160217 HS-2-027 frac.17-23 CDC13

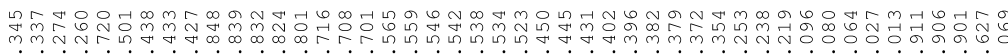

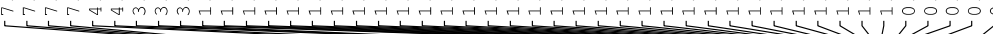
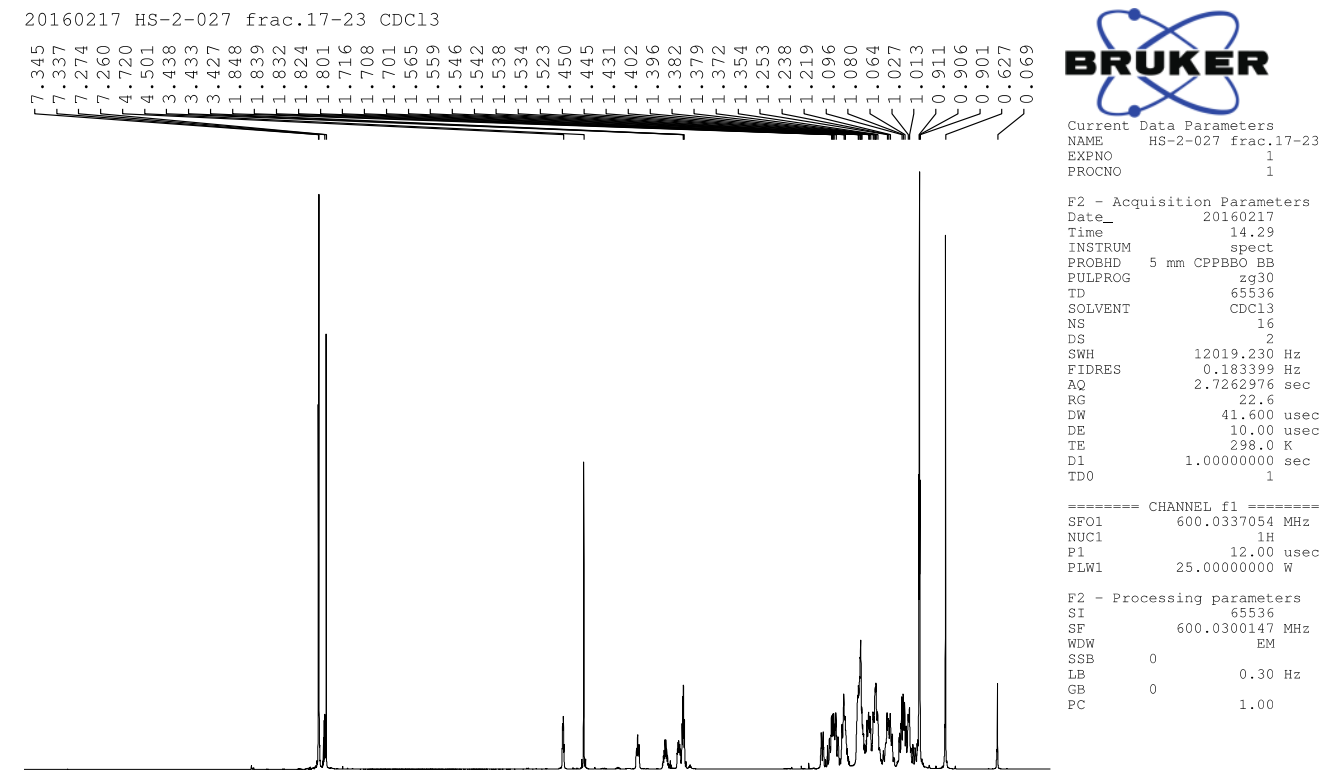

F2- Acquisition Parameters
$\begin{aligned} & \text { Date- } \\ & \text { Time }\end{aligned} \quad \begin{gathered}10217 \\ 1.29\end{gathered}$

14.29
TPEet
TNSTRUMM
PROBHD
PROPROG

$\begin{aligned} 2930 \\ \text { TD }\end{aligned}$
SOLVENT
CDC13
IS
IS

$\begin{array}{lr}\text { PS } & 2 \\ \text { SWH } & 12019.230 \mathrm{~Hz} \\ \text { EIDRES } & 0.183399 \mathrm{~Hz}\end{array}$

$\begin{array}{lr}\text { IDRES } & 0.183399 \\ \text { RQ } & 2.7262976 \mathrm{Hec} \\ \text { RG } & 22.6 \\ \text { W } & 41.600 \mathrm{usec}\end{array}$

$\begin{array}{cc}10.00 \mathrm{usec} \\ 298.0 \mathrm{~K} \\ \mathrm{TE} & 1.00000000 \mathrm{sec}\end{array}$

$======$ CHANNEL $f 1=======$
$600.0337054 \mathrm{MHz}$
SFO1
WUC1

$1 \quad 12.00$ usec

F2 - Processing parameters
$\mathrm{SI}$
$\mathrm{ST}$
$600.0300147 \mathrm{MHz}$

$\mathrm{HB}$
$\mathrm{GB}$$\quad 0.30 \mathrm{~Hz}$

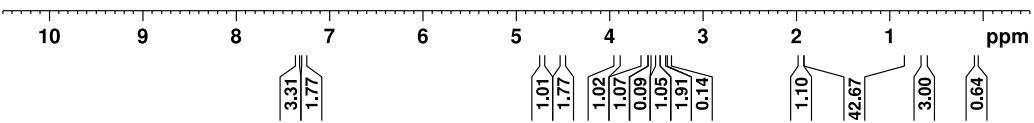

${ }^{13} \mathrm{C}$ NMR

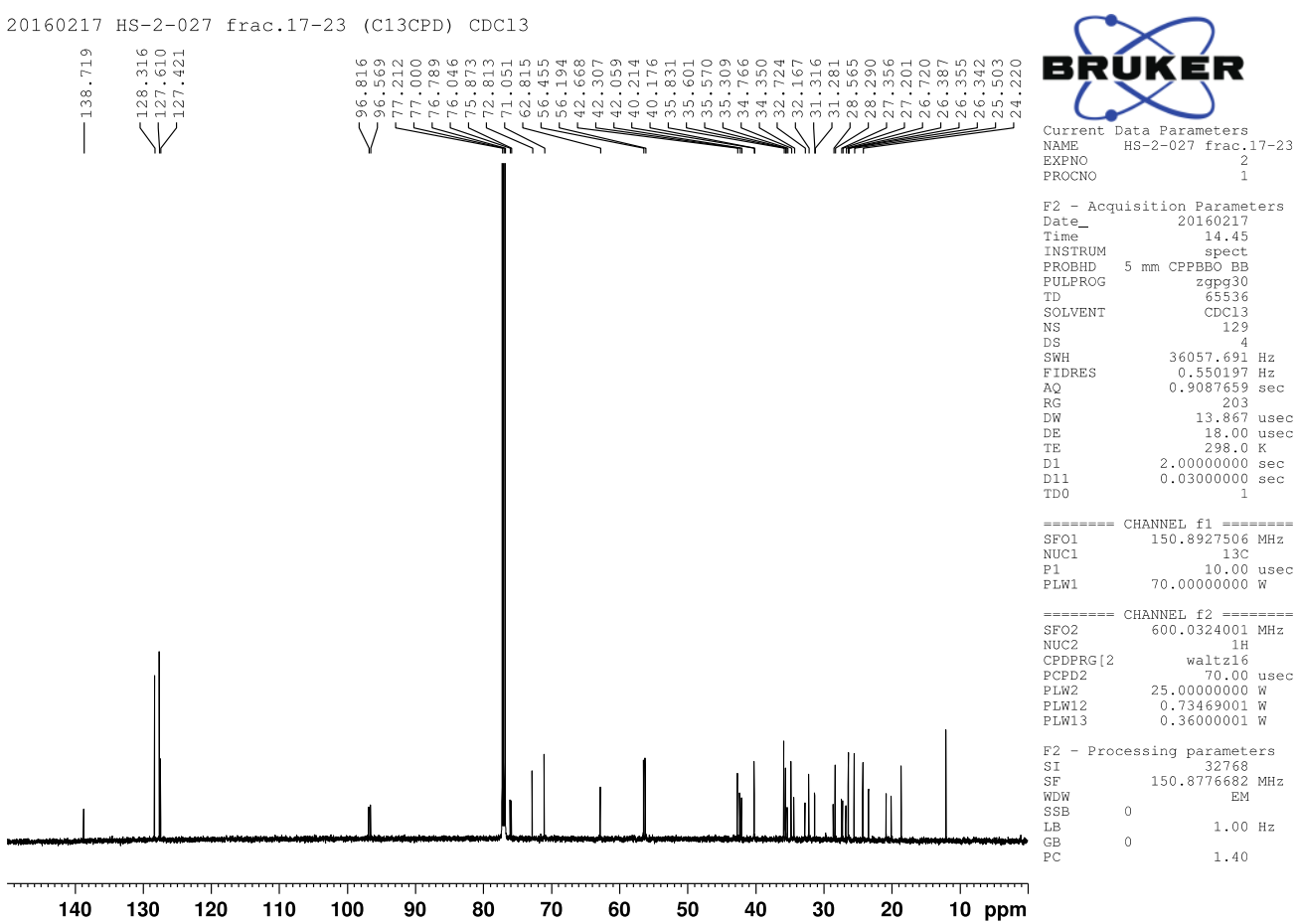


(iii) compound $\mathbf{1 1}$

${ }^{1} \mathrm{H}$ NMR

20150422 HS-2-070 frac.43-61 CDCl3

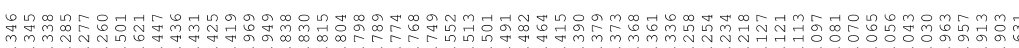

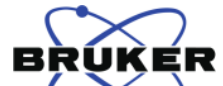

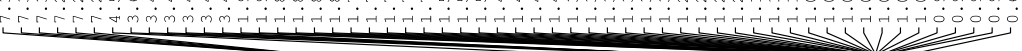
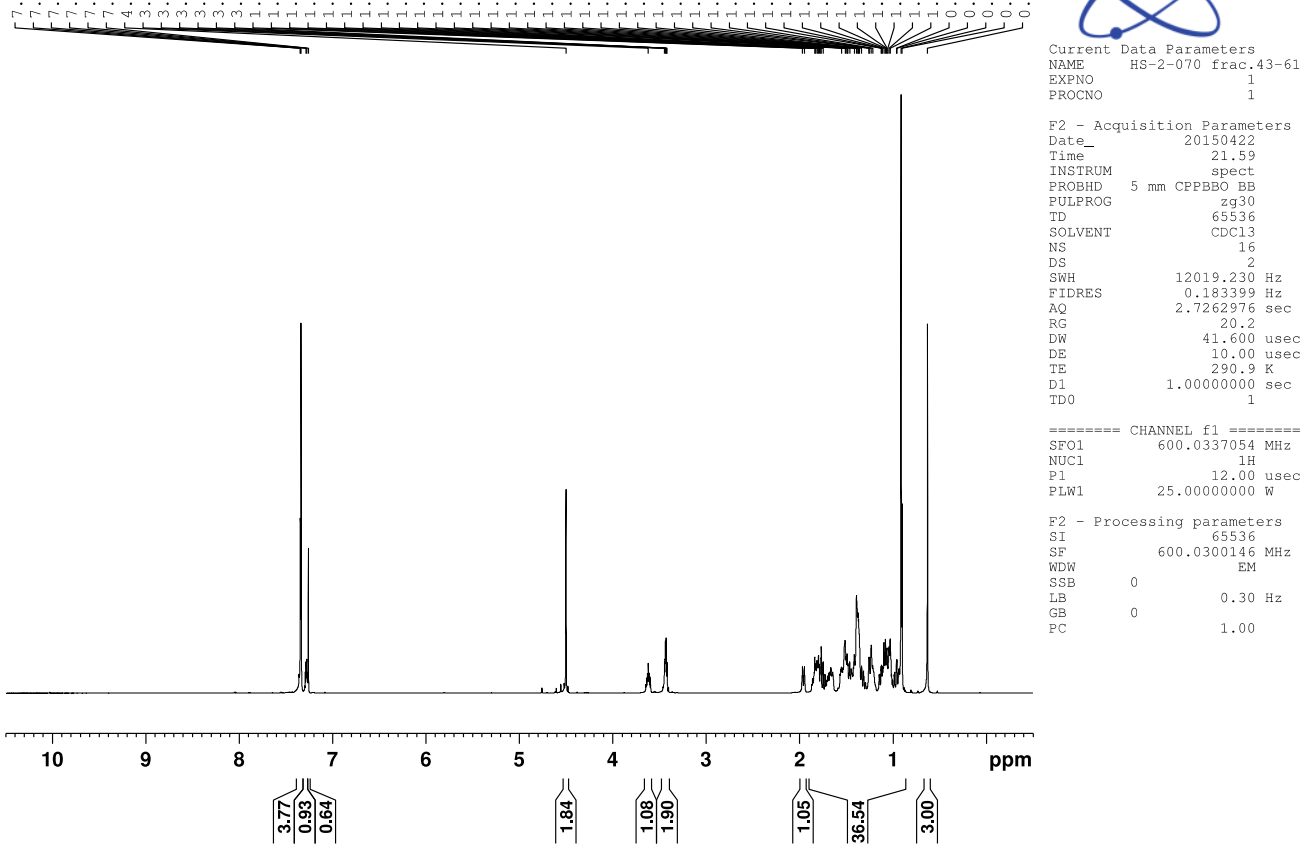

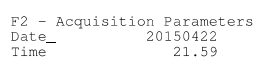

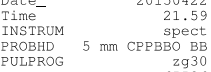

$\begin{array}{lr}\text { PULPROG } & \text { zg30 } \\ \text { TD } & 65536 \\ \text { SOLVENT } & \text { CDC13 } 16 \\ \text { NS } & 16 \\ \text { DS } & 2\end{array}$

\begin{tabular}{lr} 
& 2019 \\
SWH & $230 \mathrm{~Hz}$ \\
IDRES & $0.183399 \mathrm{~Hz}$ \\
\hline & $2.7262976 \mathrm{sec}$
\end{tabular}

$\begin{array}{cr}\text { RQ } & 2.7262 .2 \mathrm{sec} \\ \mathrm{RG} & 20.2 \mathrm{usec} \\ \mathrm{DW} & 41.600 \mathrm{us} \\ \mathrm{DE} & 10.00 \mathrm{usec} \\ \mathrm{DE} & 290.9 \mathrm{~K} \\ \mathrm{DE} & \\ \mathrm{D} & \end{array}$

$======$
SFO1

NUC1 $\quad 12.00 \mathrm{usec}$

F2 - Processing parameters
SI
605536
$600.0300146 \mathrm{MH}$

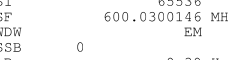

$\begin{array}{ll}\underset{G B}{G B} & 0 \\ P C & 0.30 \mathrm{~Hz} \\ P B & 1.00\end{array}$

${ }^{13} \mathrm{C}$ NMR

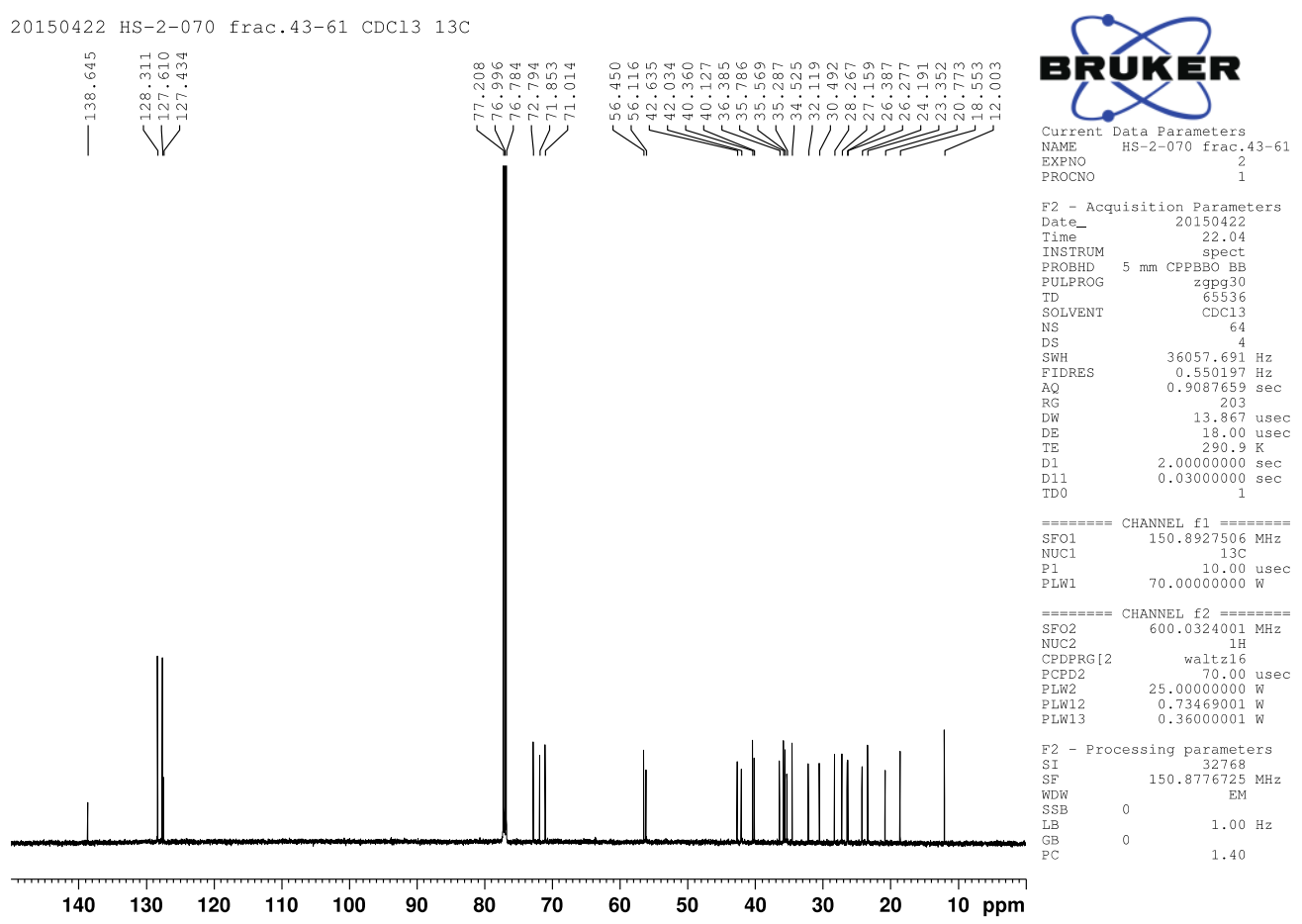


(iv) compound 12

${ }^{1} \mathrm{H}$ NMR

20150422 HS-2-076 frac.30-70 CDC13

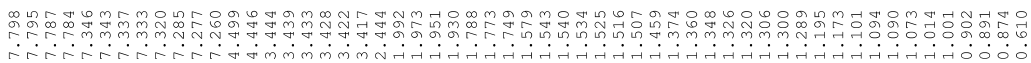
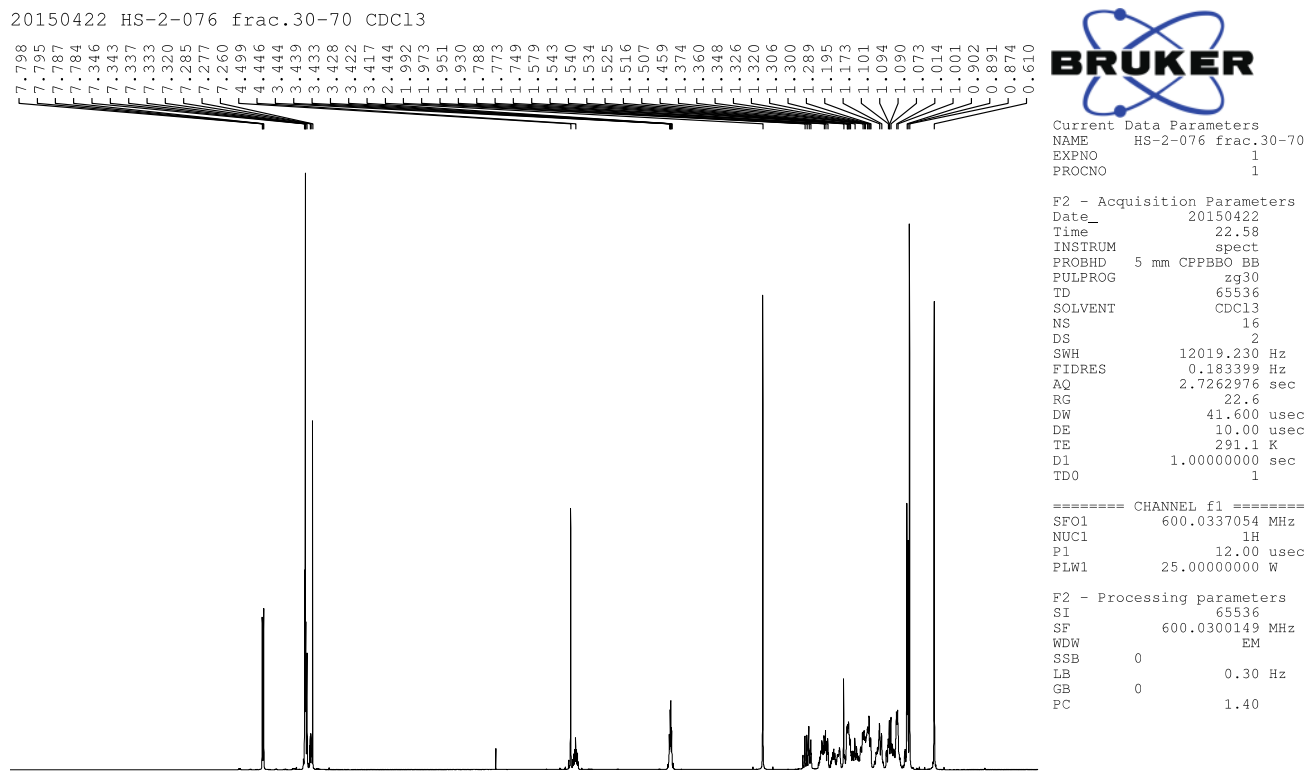

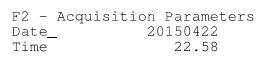

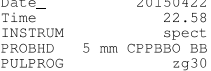

$\begin{array}{lr}\text { TULPROG } & \mathrm{zg} 30 \\ \text { TD } & 65536 \\ \text { SOLVENT } & \mathrm{CDC13} \\ \text { NS } & 16 \\ \text { NS } & 2\end{array}$

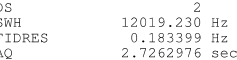

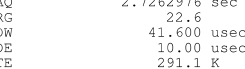

1.00000000
1000

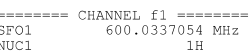

12.00
usec

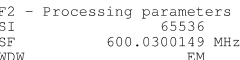

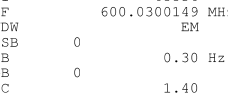

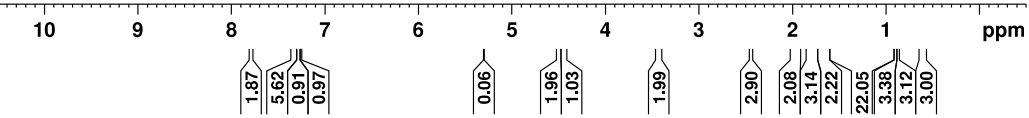

萬

:

${ }^{13} \mathrm{C}$ NMR

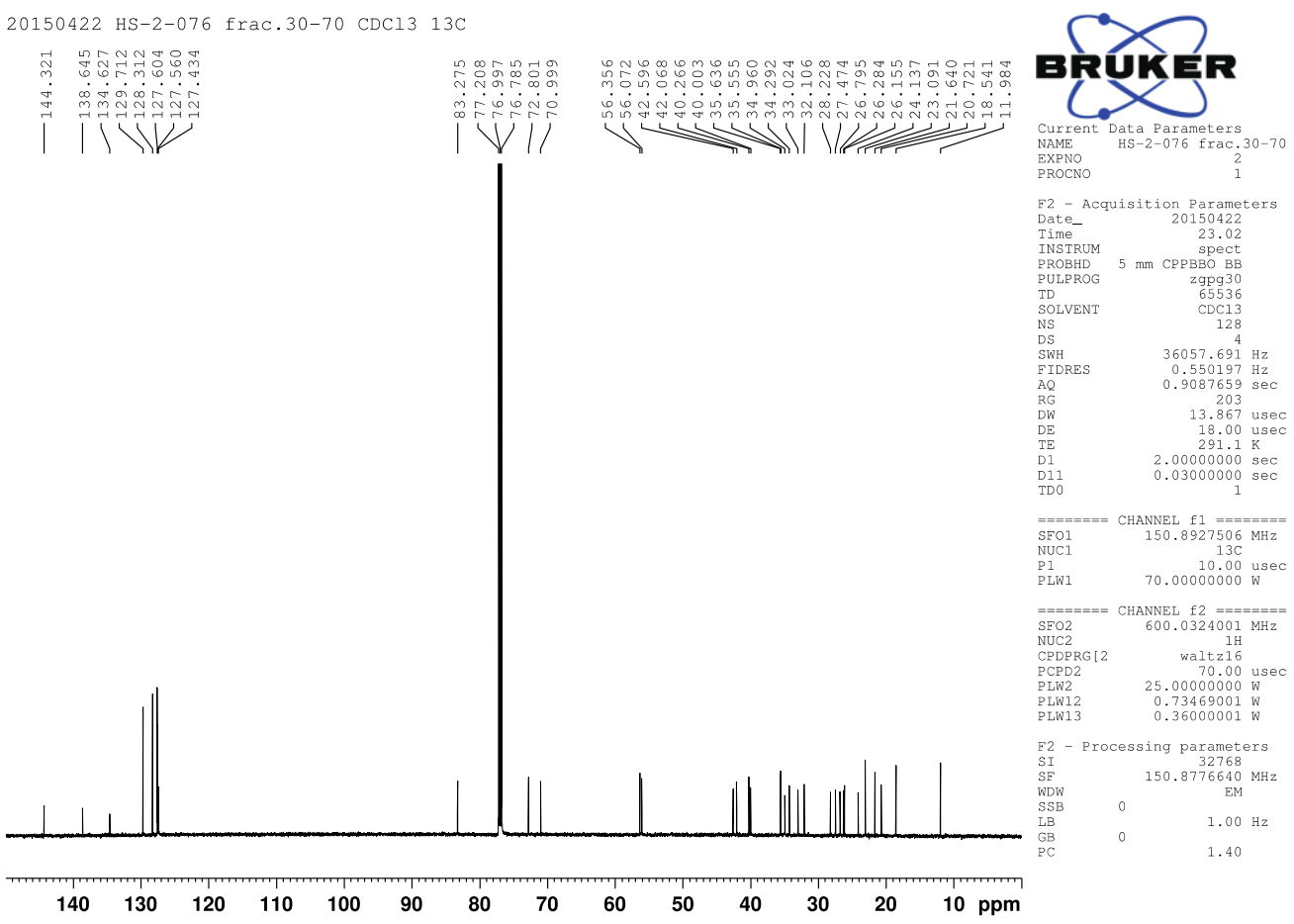


(v) compound $\mathbf{1 3}$

${ }^{1} \mathrm{H}$ NMR

20160303 HS-2-081 frac.2_11-15 CDC13

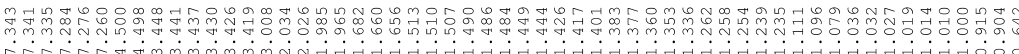

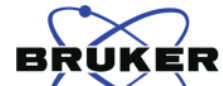

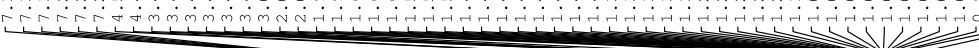
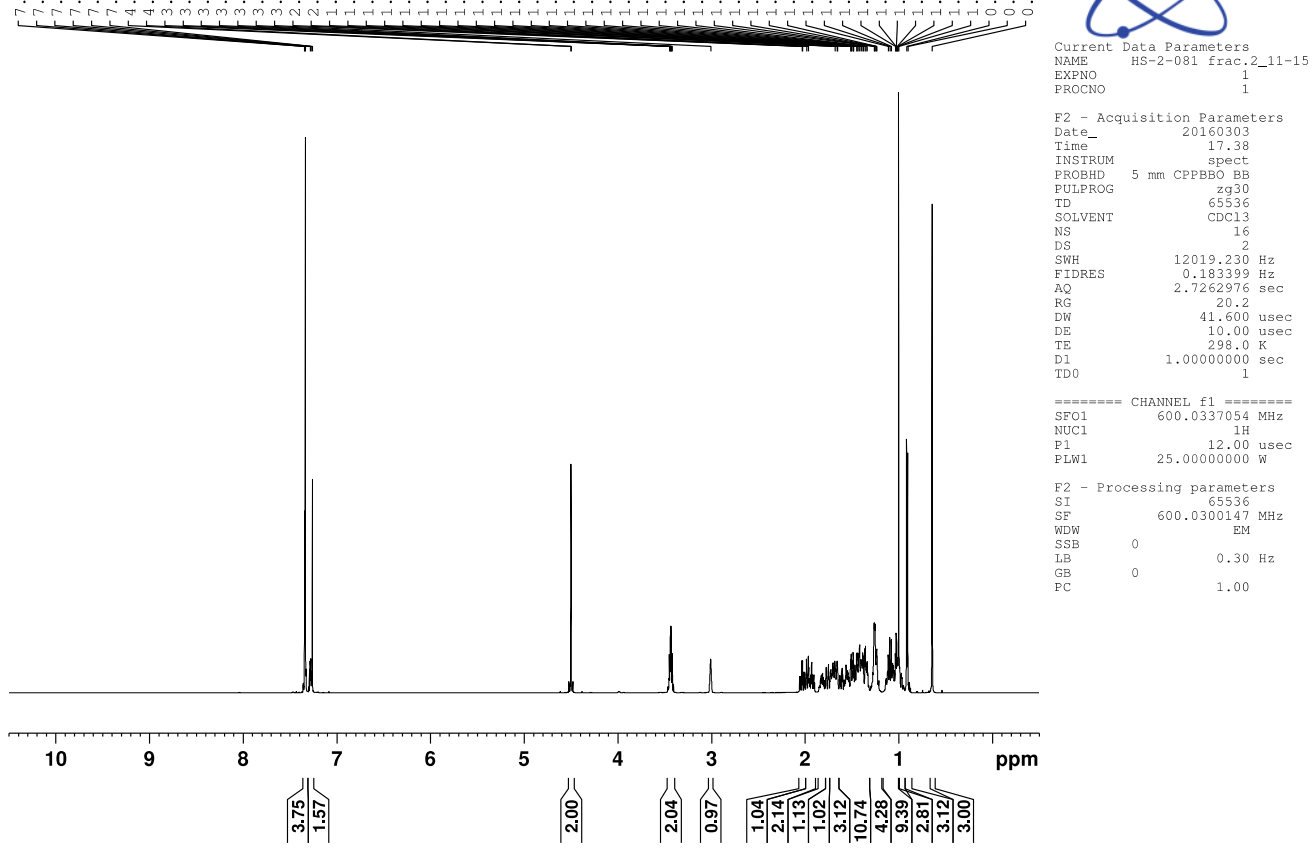

${ }^{13} \mathrm{C}$ NMR

20160303 HS-2-081 frac.2_11-15 CDC13 13C

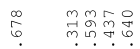

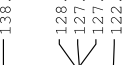

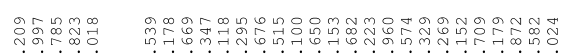

Vil
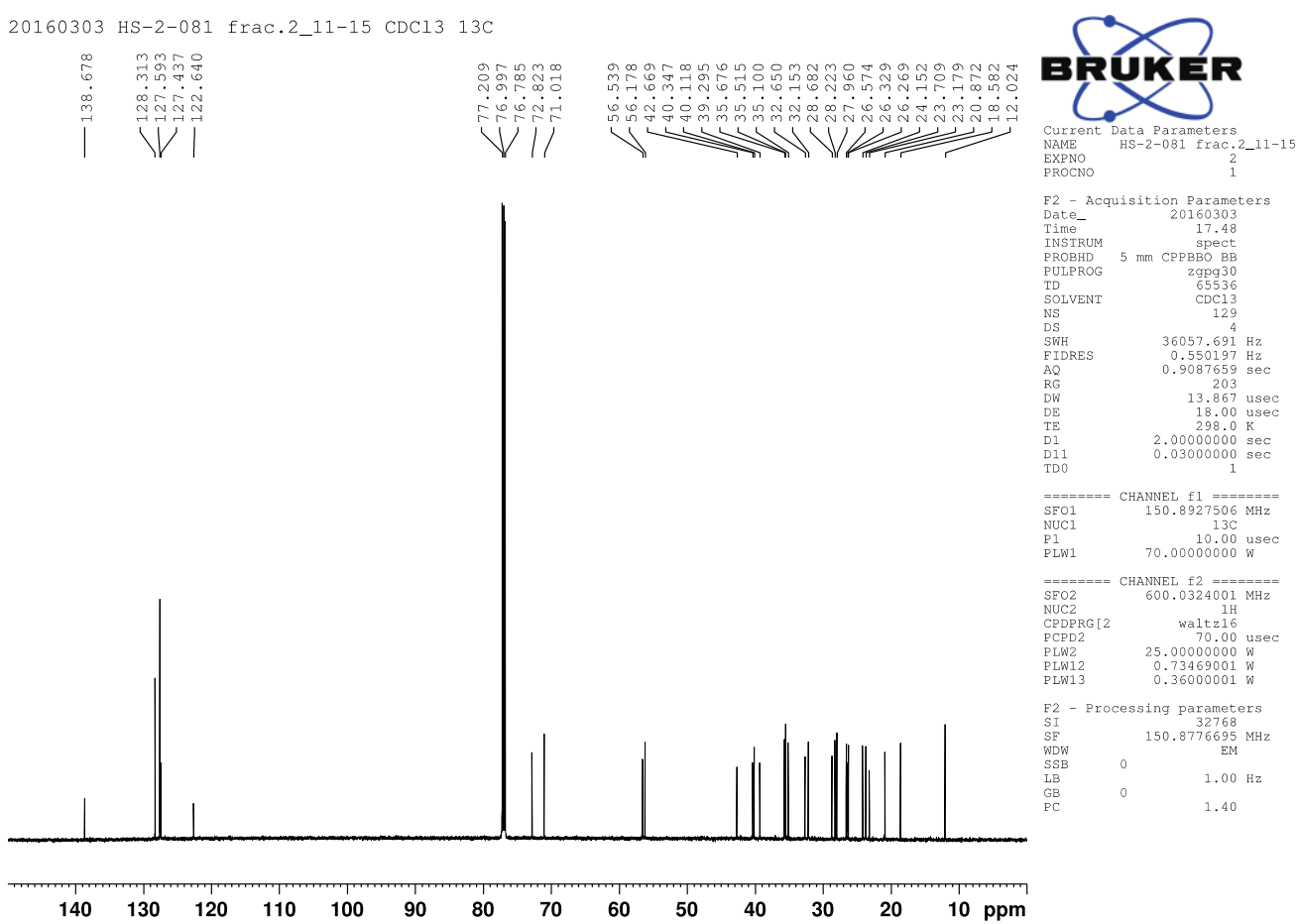

$\begin{array}{lllllllllllllll}140 & 130 & 120 & 110 & 100 & 90 & 80 & 70 & 60 & 50 & 40 & 30 & 20 & 10 & \mathrm{ppm}\end{array}$ 
(vi) compound 14a

${ }^{1} \mathrm{H}$ NMR

20200626.MM1-92.column3.f10-20.CDCl3
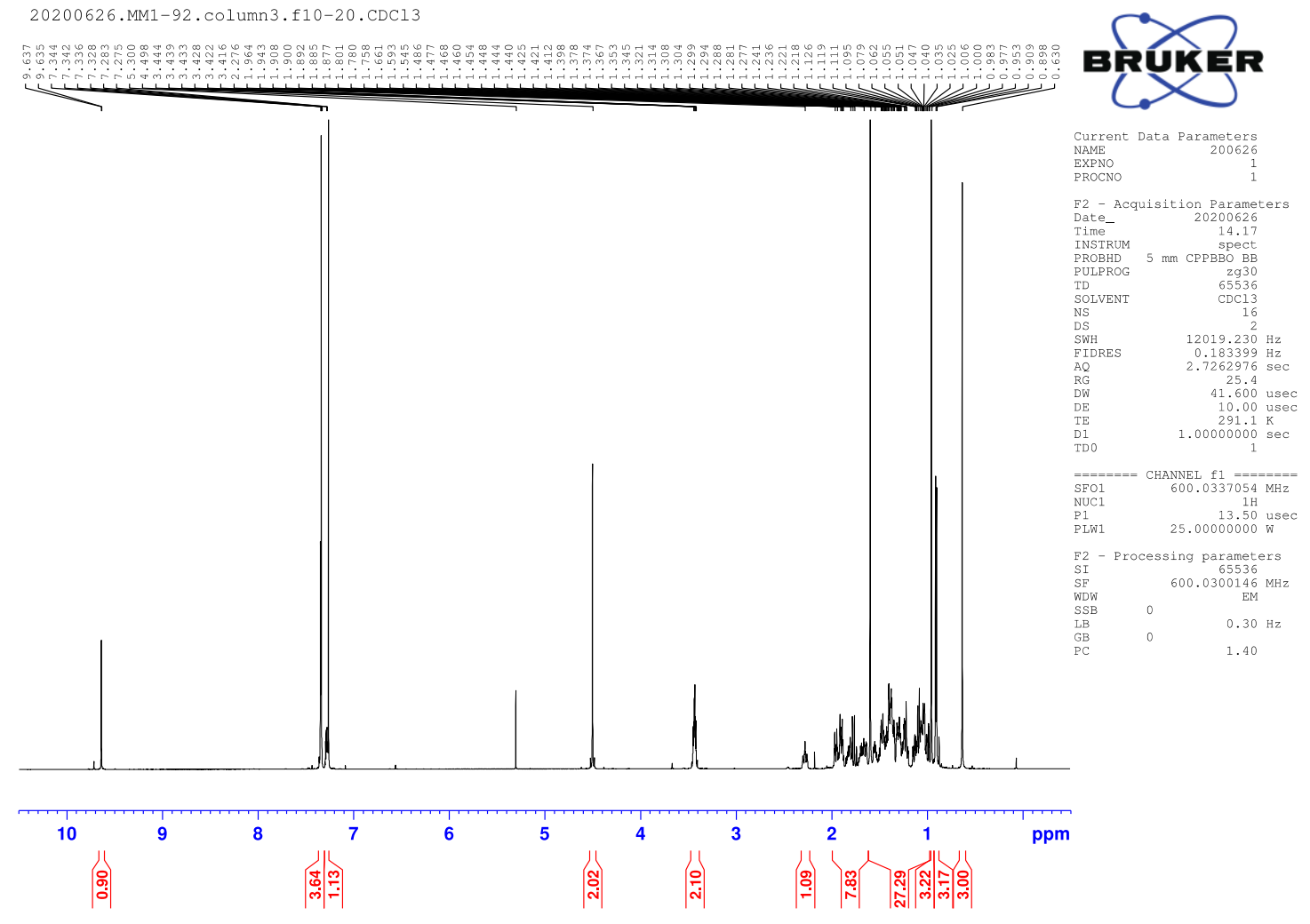

${ }^{13} \mathrm{C}$ NMR

20200626.MM1-92.column3.f10-20.CDC13

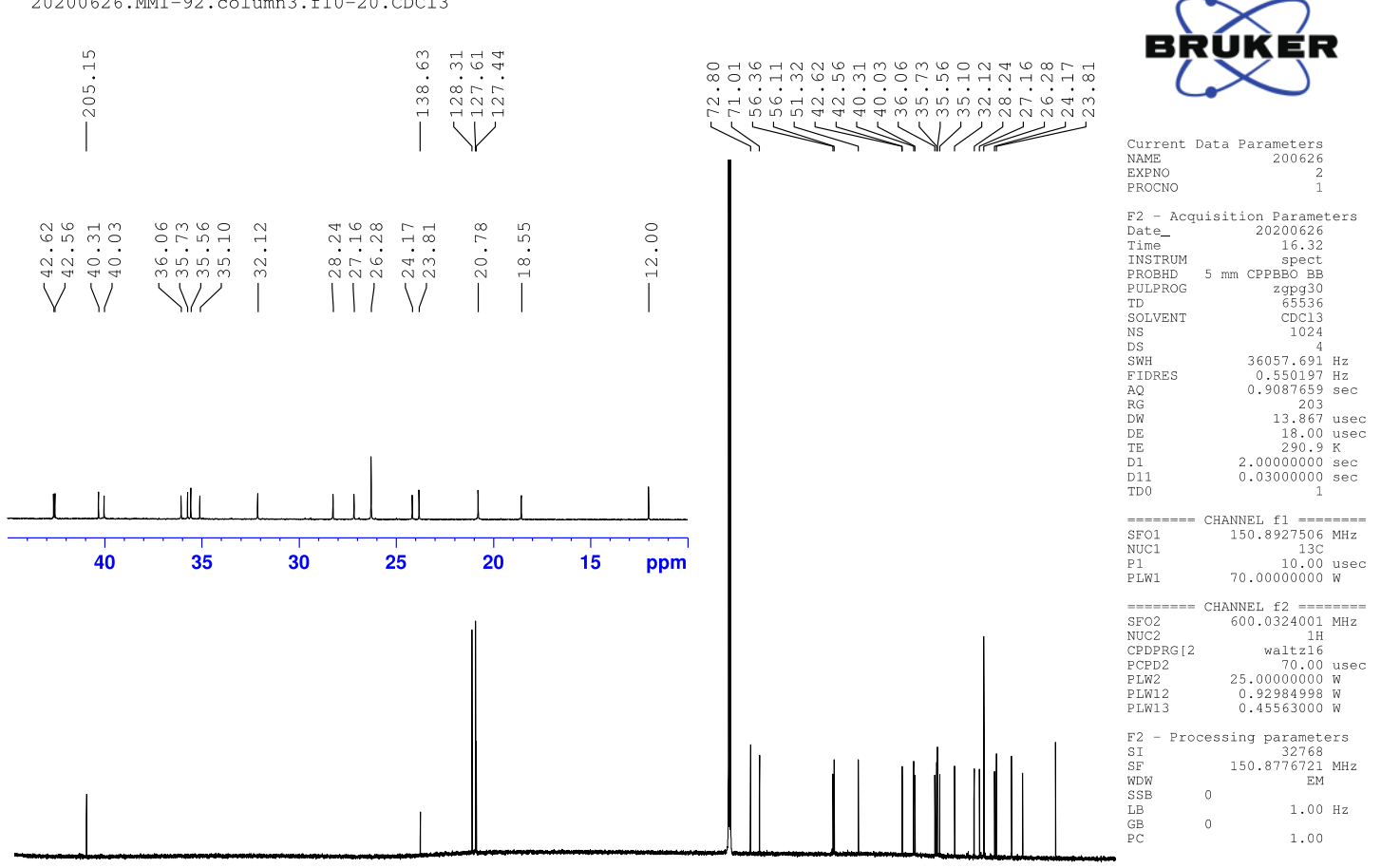

$\begin{array}{lllllllllllllllllllll}210 & 200 & 190 & 180 & 170 & 160 & 150 & 140 & 130 & 120 & 110 & 100 & 90 & 80 & 70 & 60 & 50 & 40 & 30 & 20 & \mathrm{ppm}\end{array}$ 
(vii) compound 14b

${ }^{1} \mathrm{H}$ NMR

20160308 HK-1-060 frac. 4 CDC13

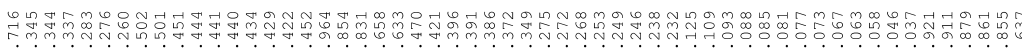
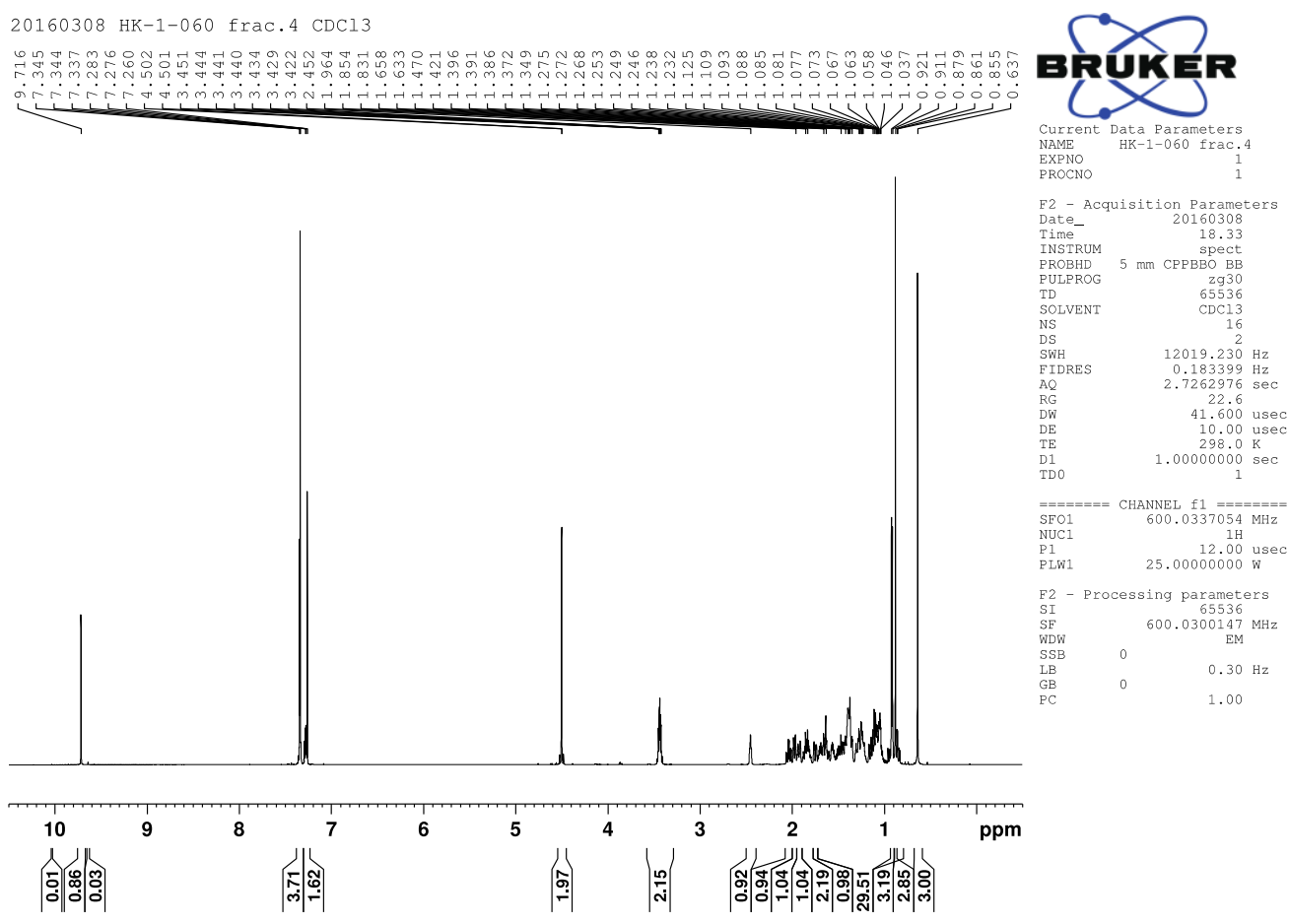

${ }^{13} \mathrm{C}$ NMR

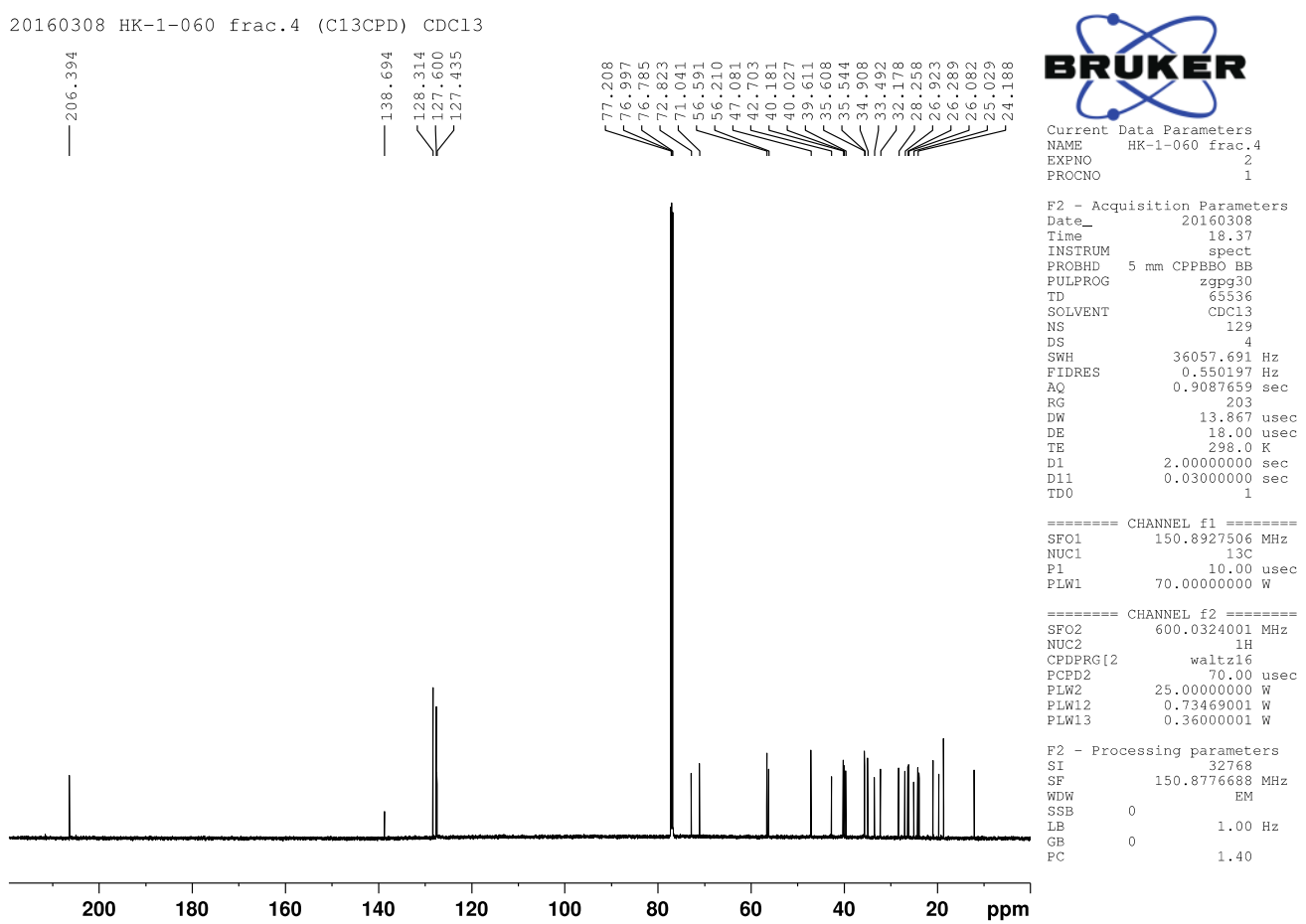


(viii) compound $\mathbf{1 5}$

${ }^{1} \mathrm{H}$ NMR

HS 20131203 3A-COOH crude CDCl3

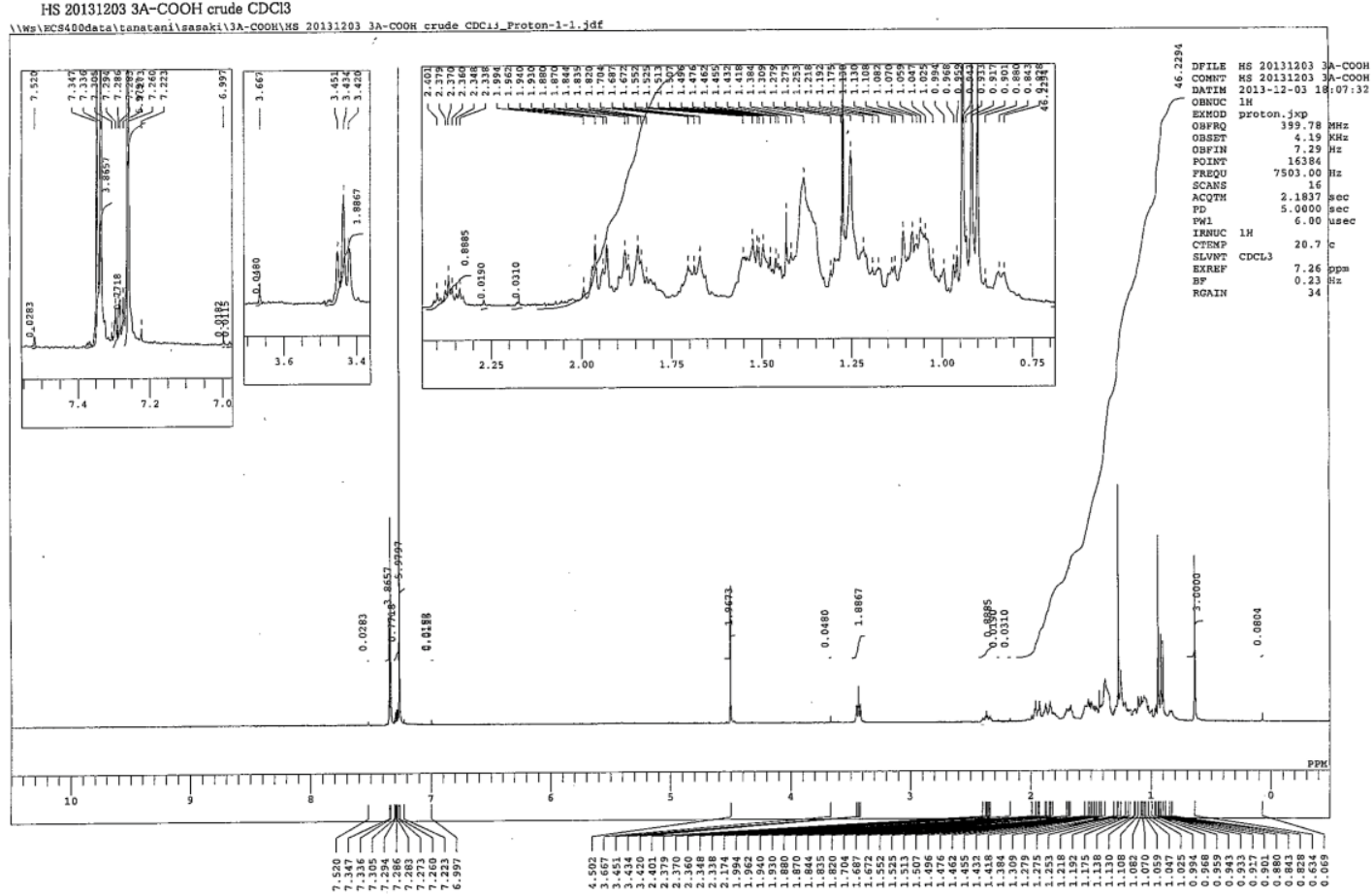

\section{${ }^{13} \mathrm{C}$ NMR}

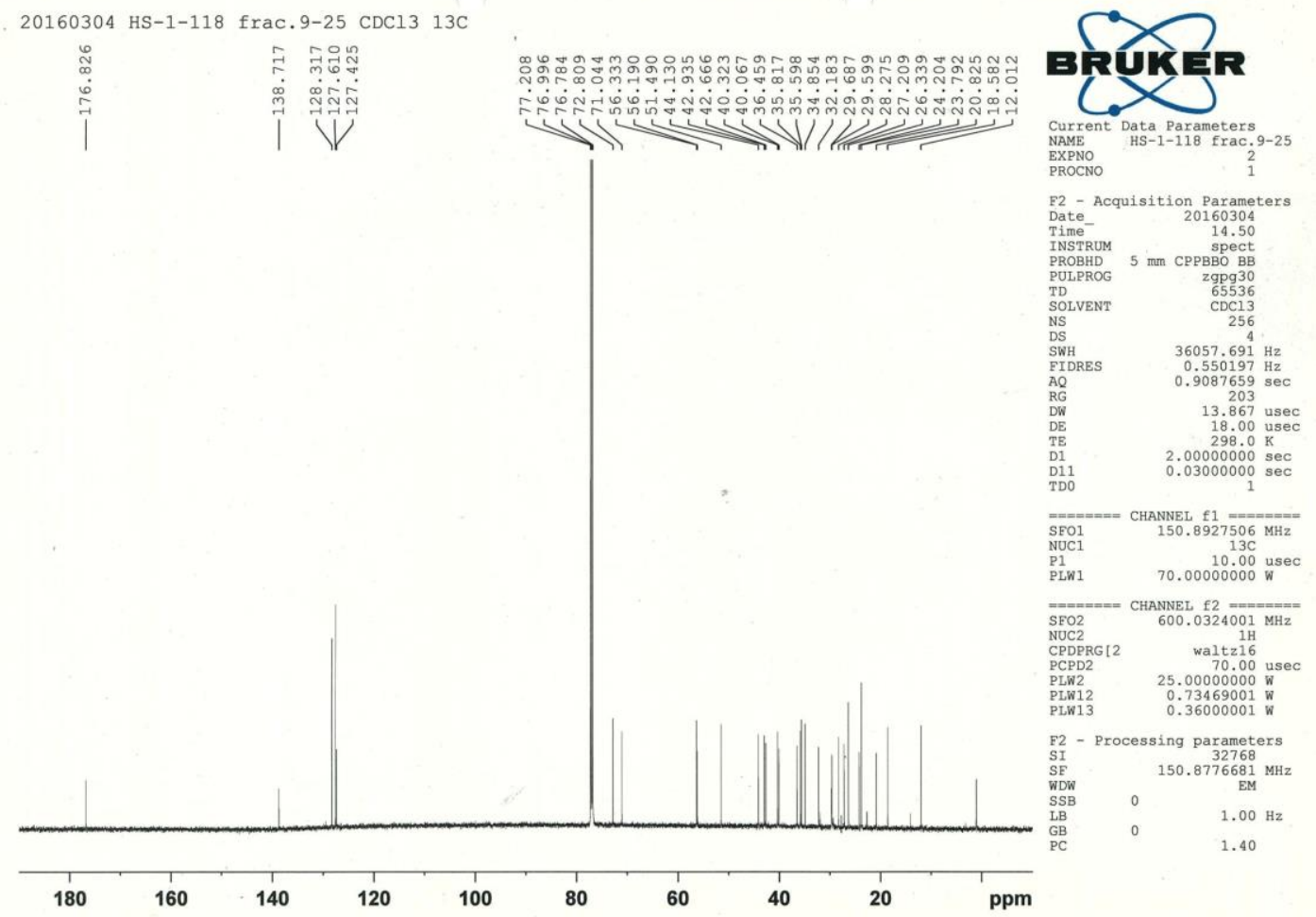


(ix) compound 16

${ }^{1} \mathrm{H}$ NMR
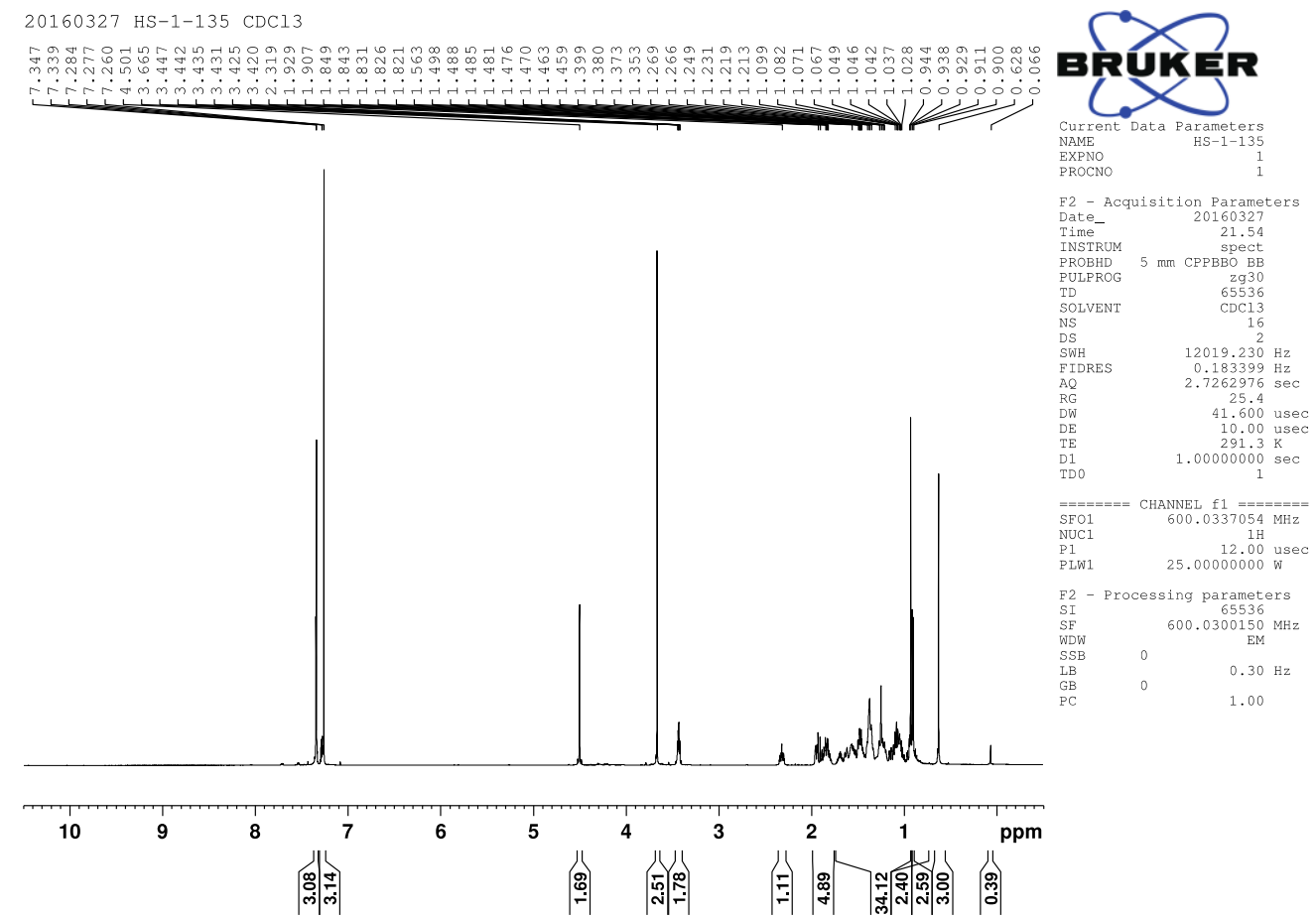

${ }^{13} \mathrm{C}$ NMR

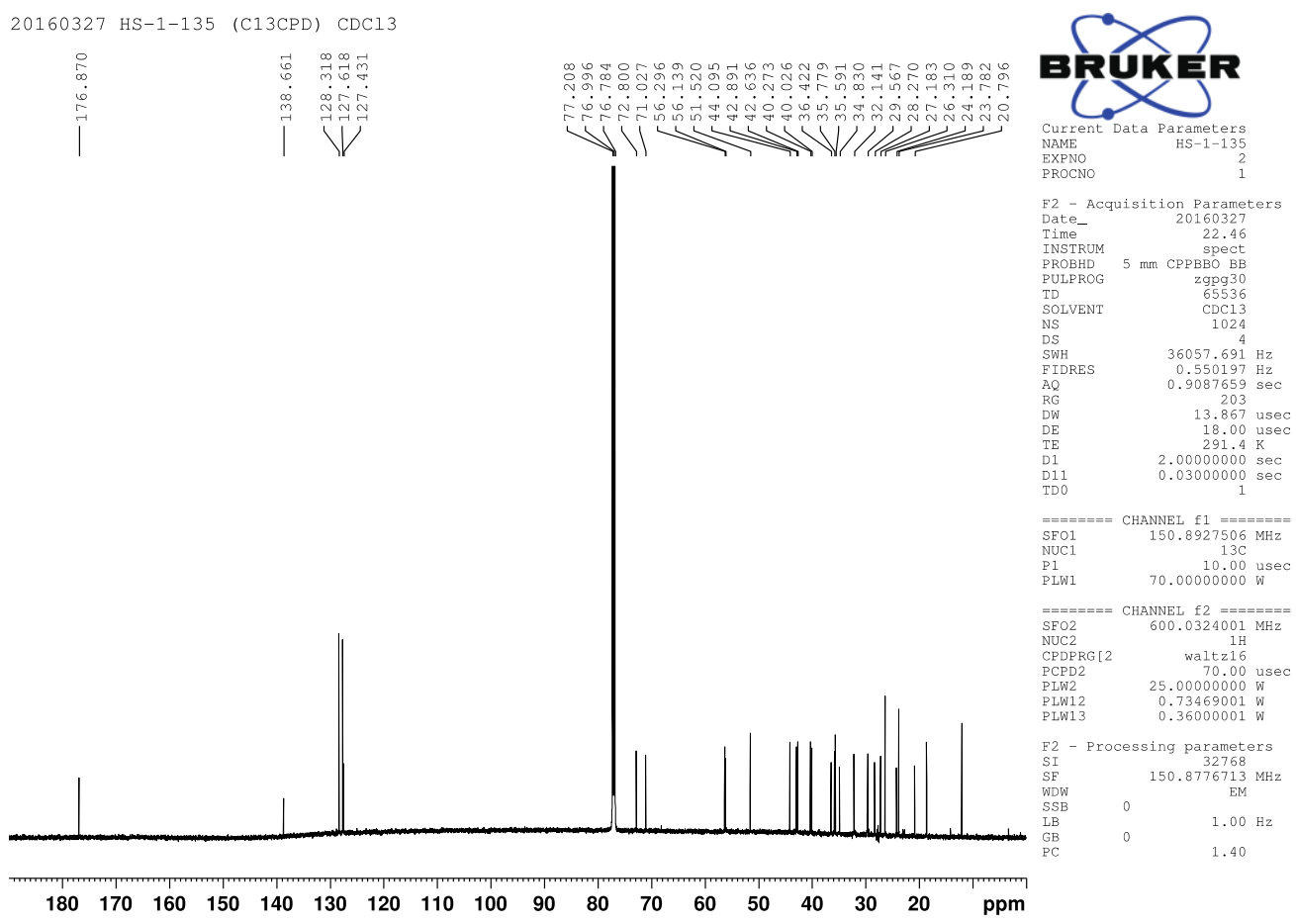


(x) compound 17

${ }^{1} \mathrm{H}$ NMR

20200615. HS. compd17. CDCC13.1H

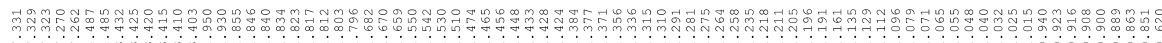

BRUKER

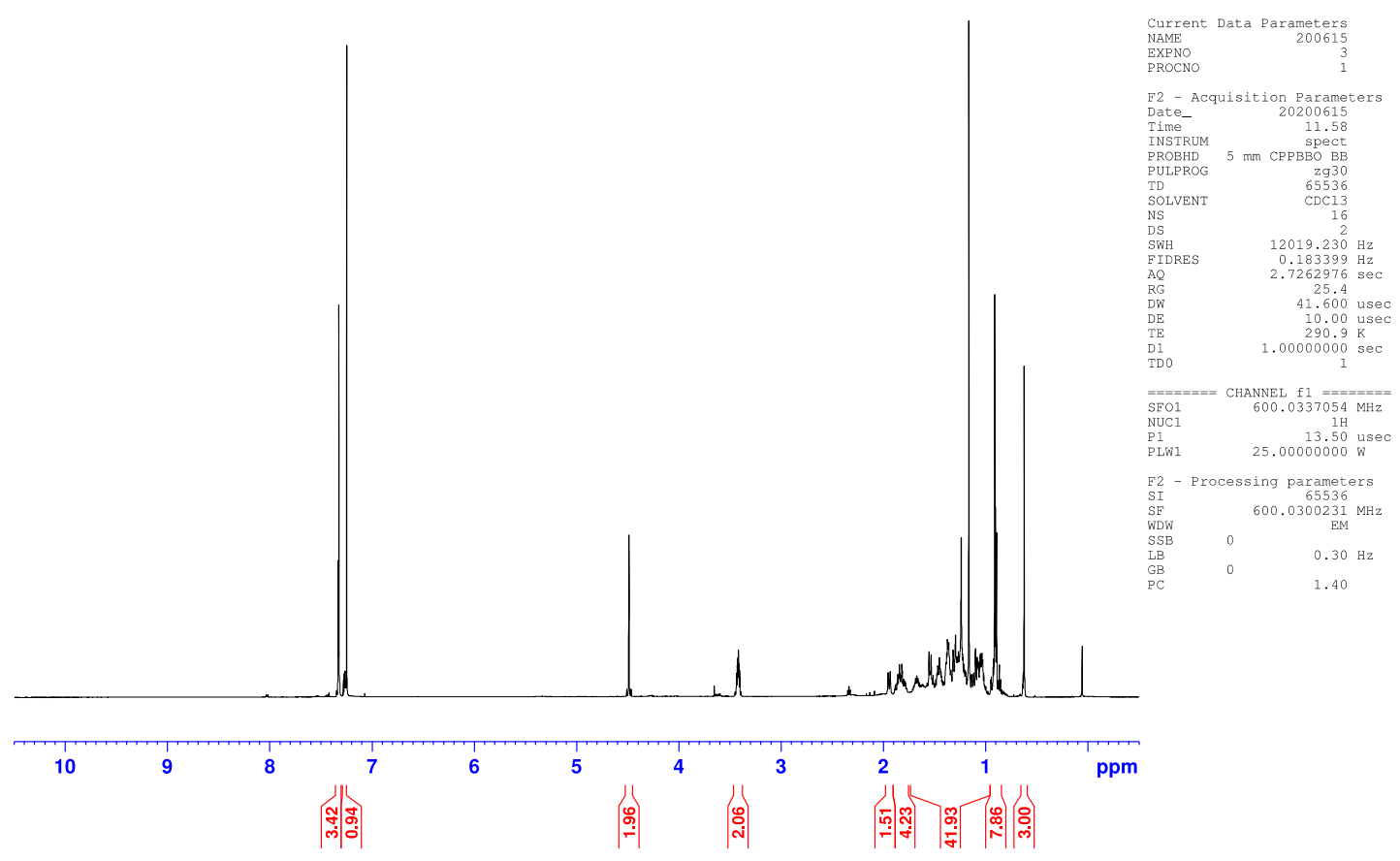

${ }^{13} \mathrm{C}$ NMR

20200615.HS. Compd17.CDC13.13C

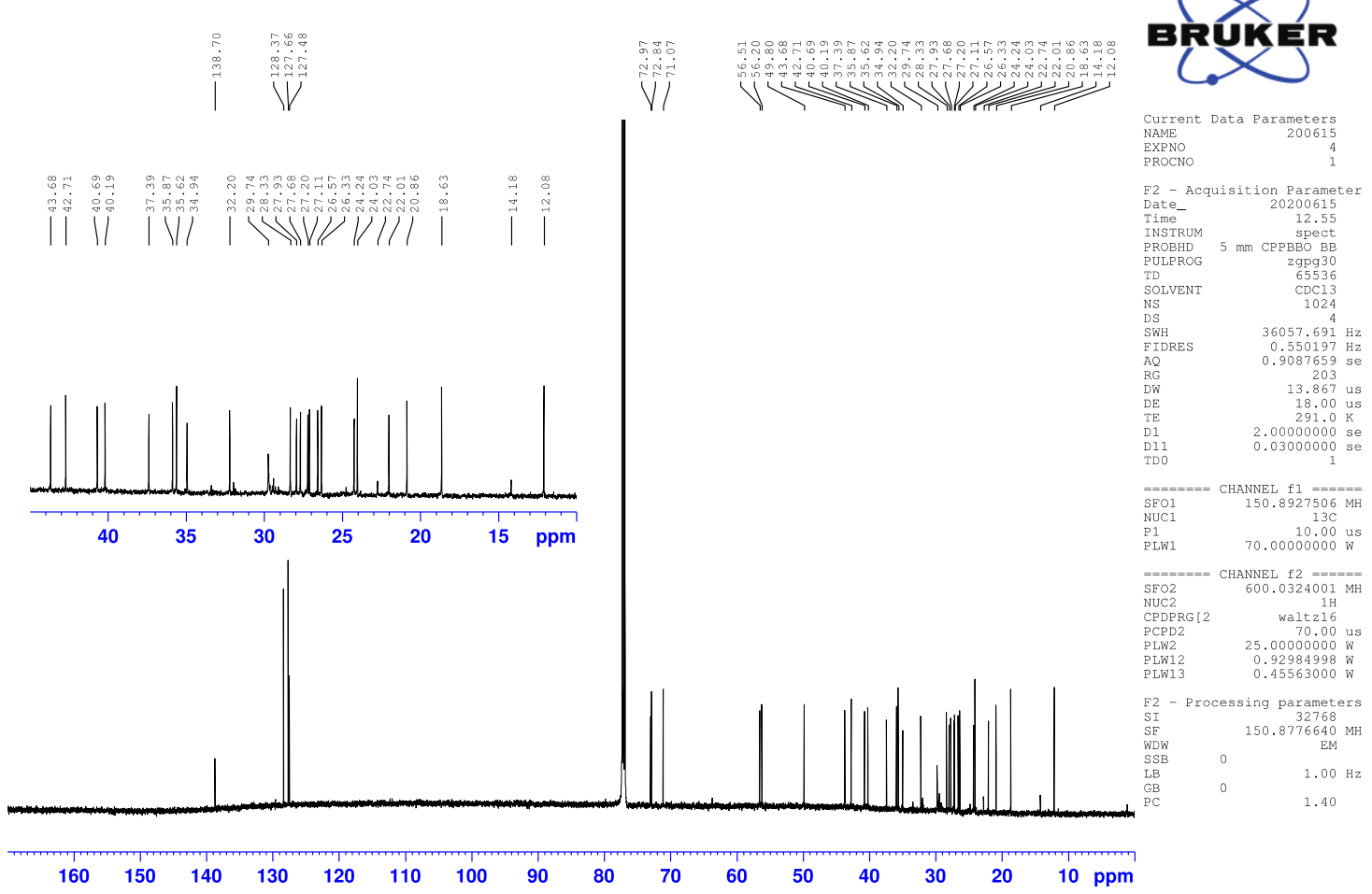


(xi) compound 5

${ }^{1} \mathrm{H}$ NMR
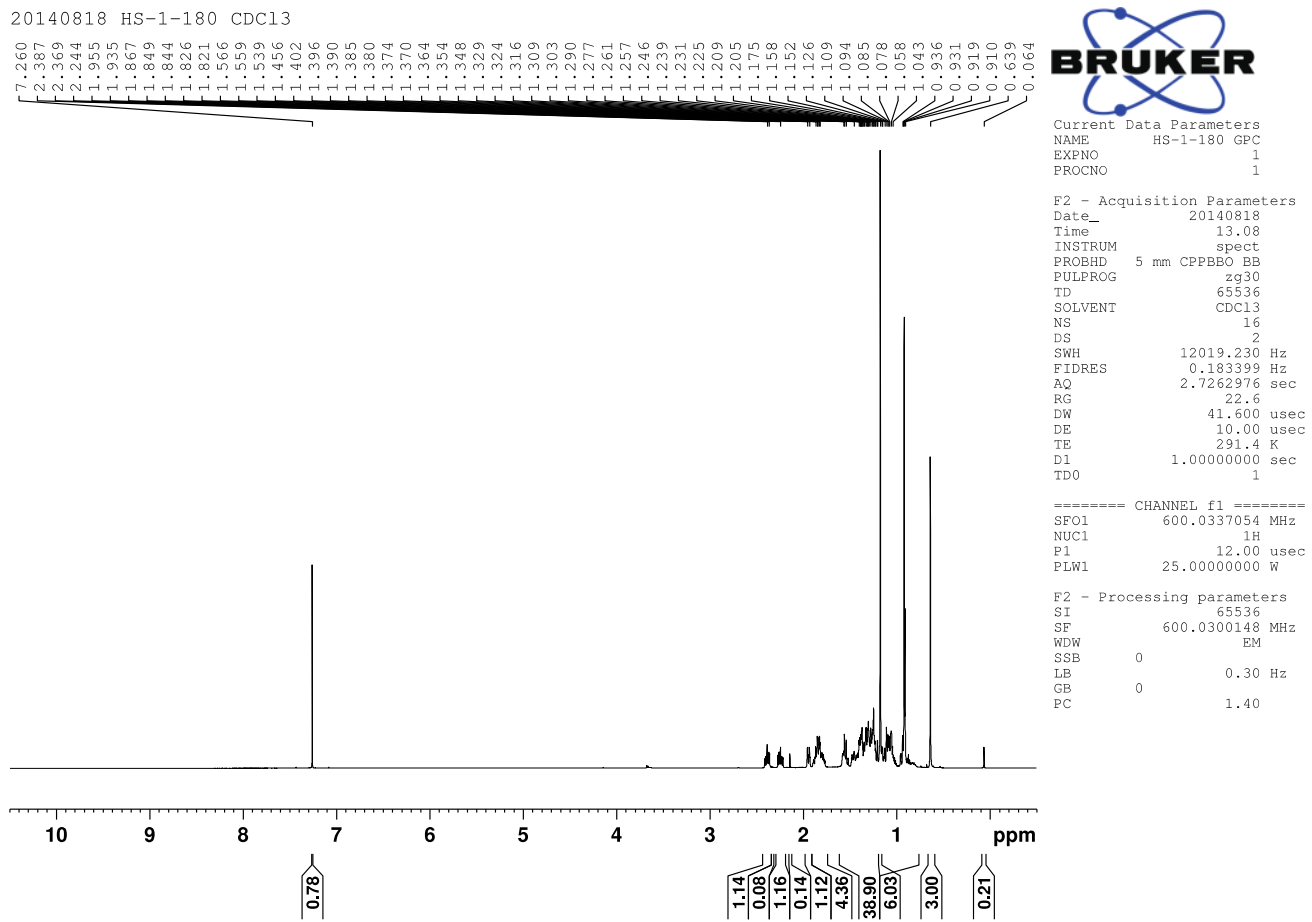

${ }^{13} \mathrm{C}$ NMR

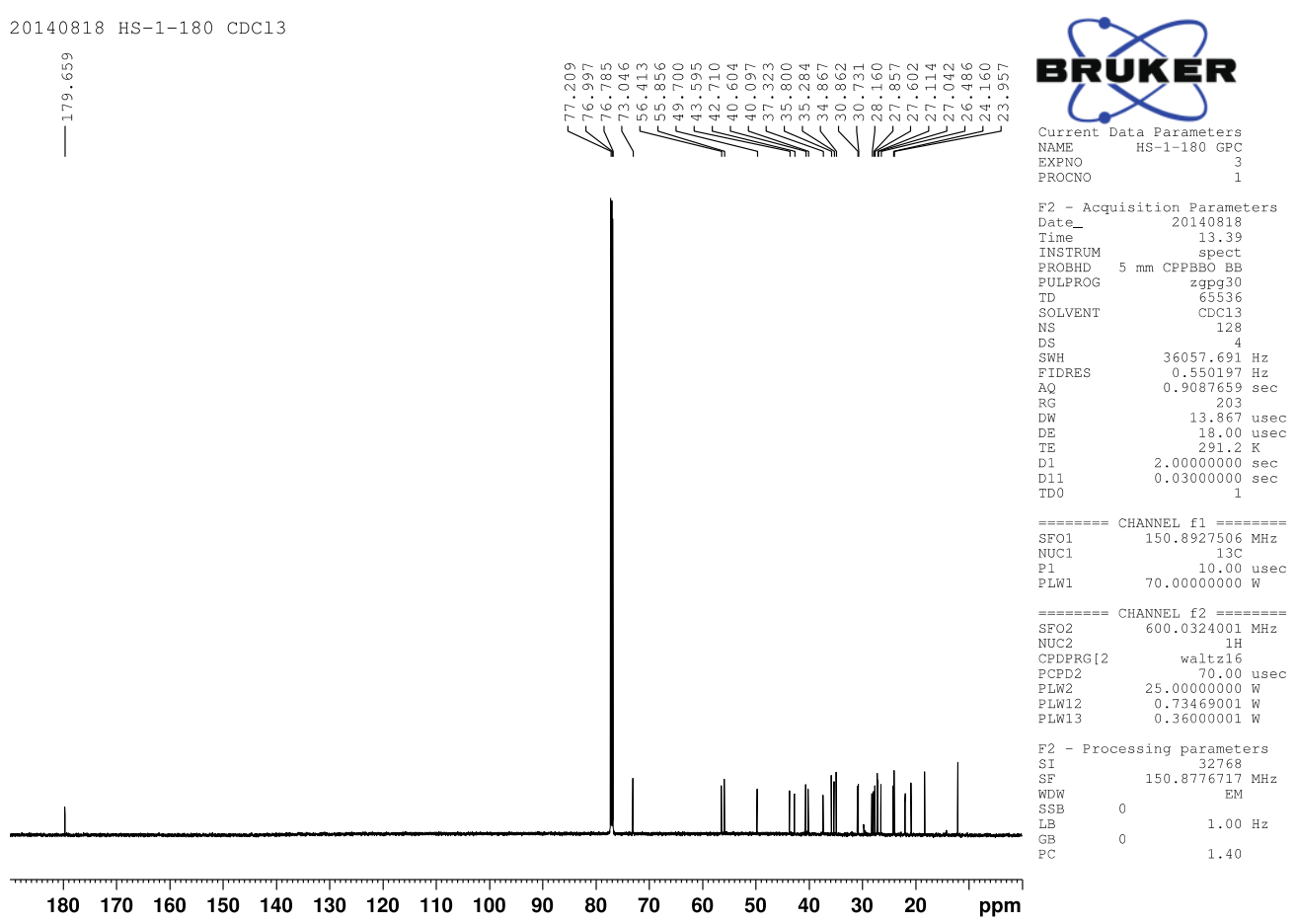


(xii) compound 19a

${ }^{1} \mathrm{H}$ NMR

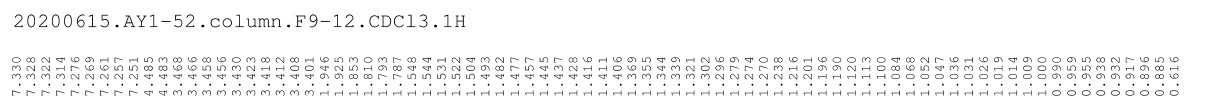

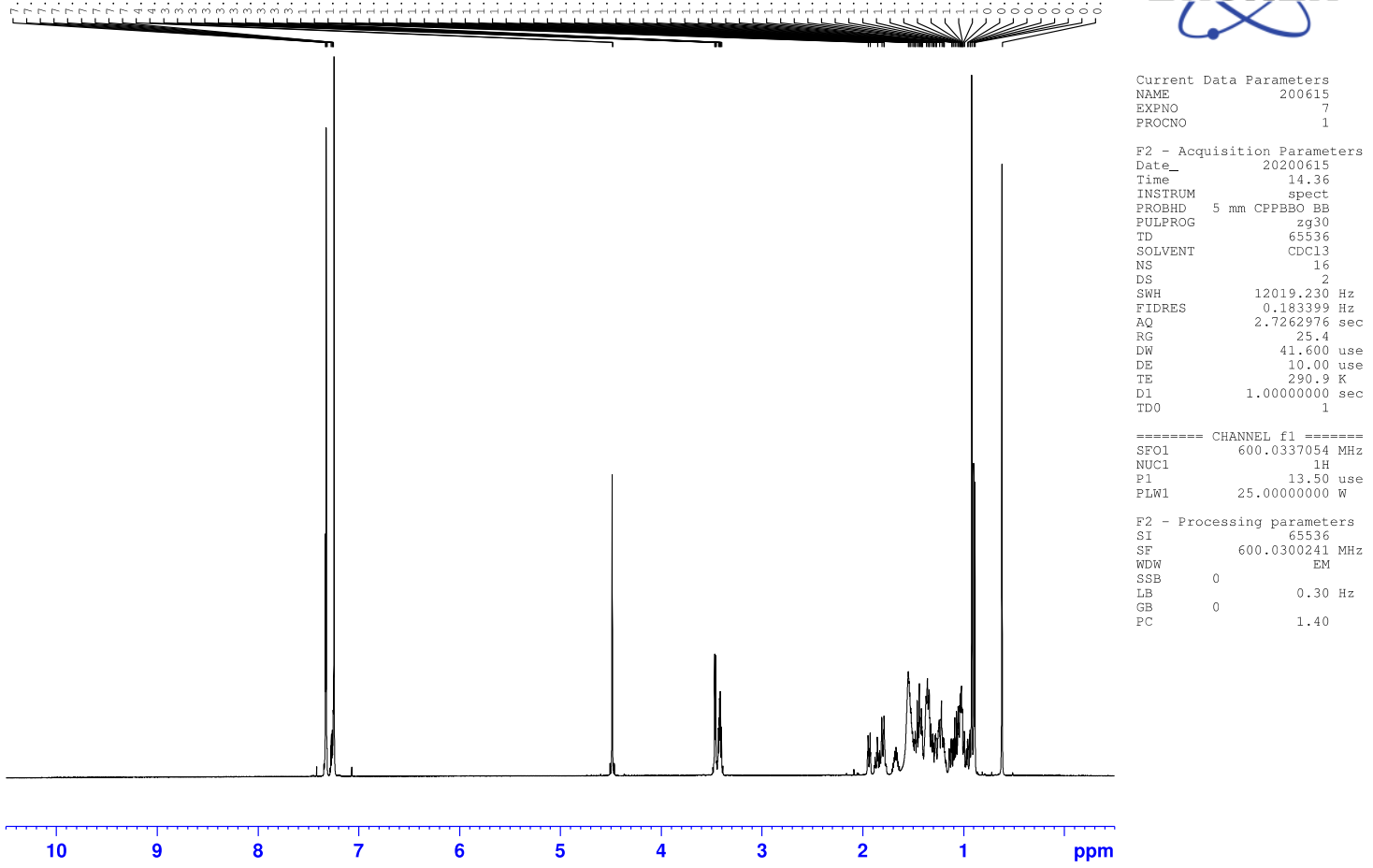

${ }^{13} \mathrm{C}$ NMR

20200615.AY1-52.Column.F9-12.CDC13.13C

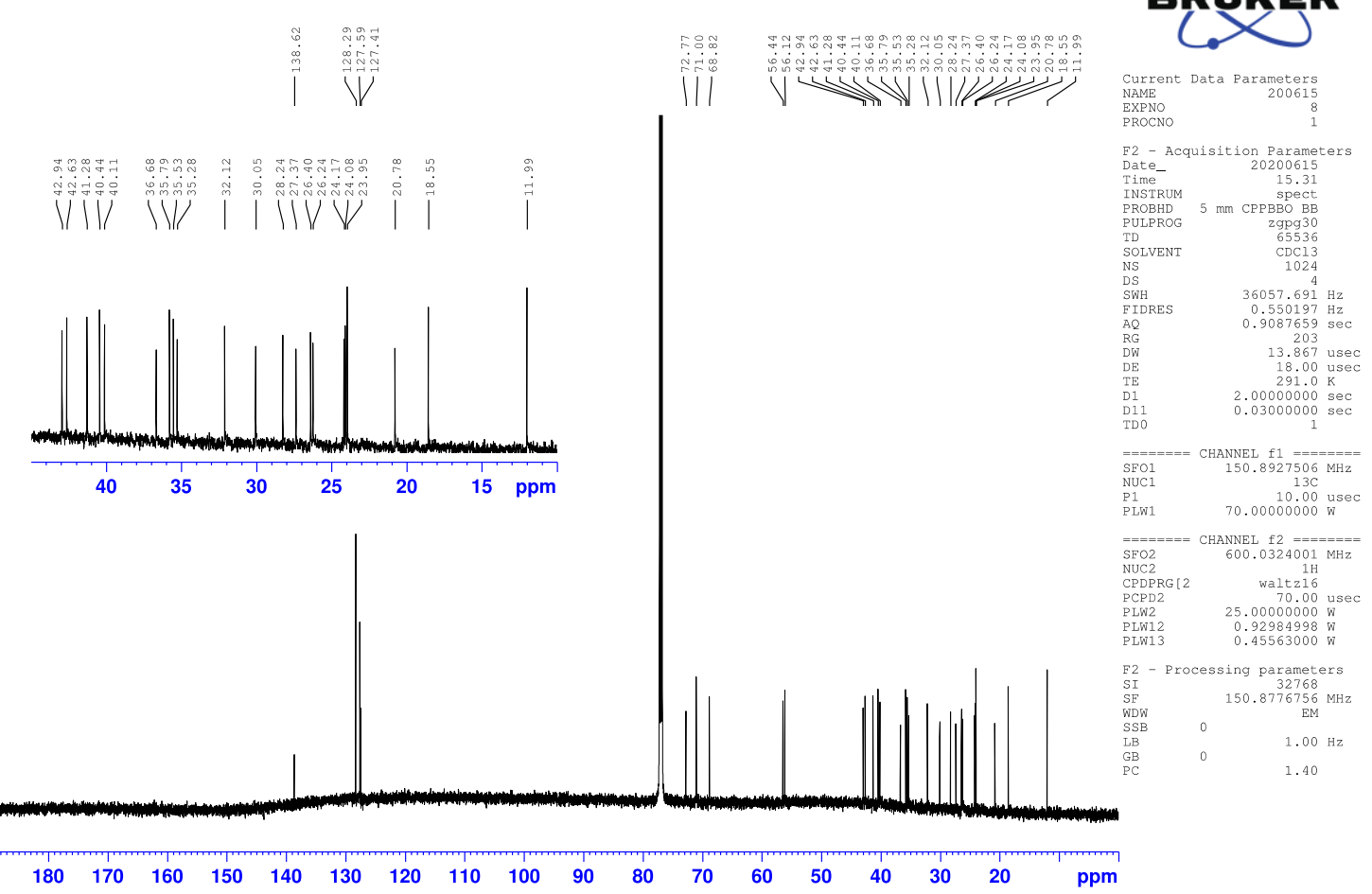


(xiii) compound 19b

${ }^{1} \mathrm{H}$ NMR

20160326 HS-2-184 frac.2_1-21 CDCl3

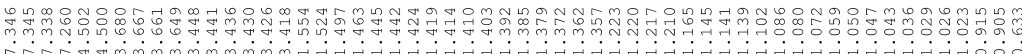
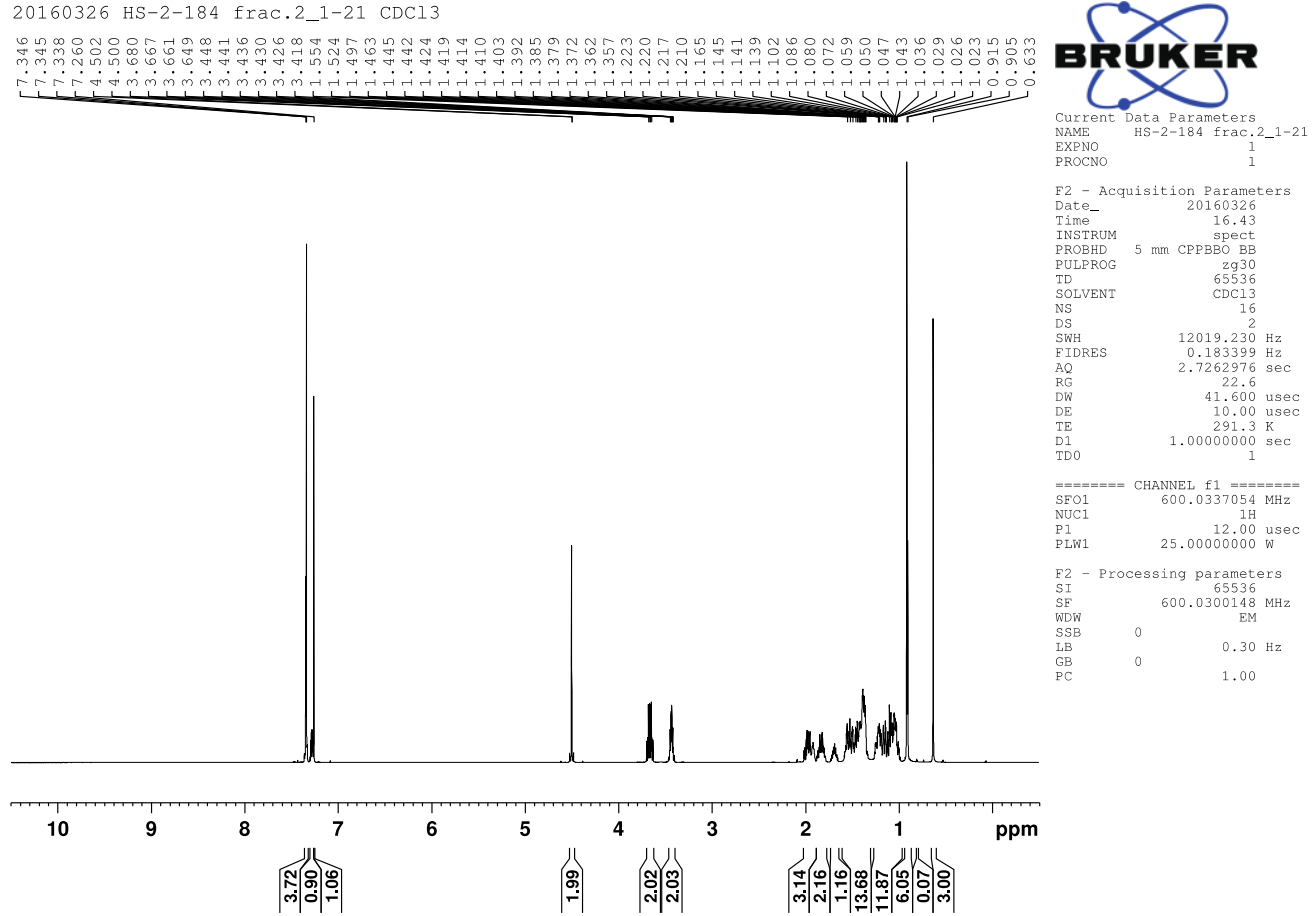

${ }^{13} \mathrm{C}$ NMR

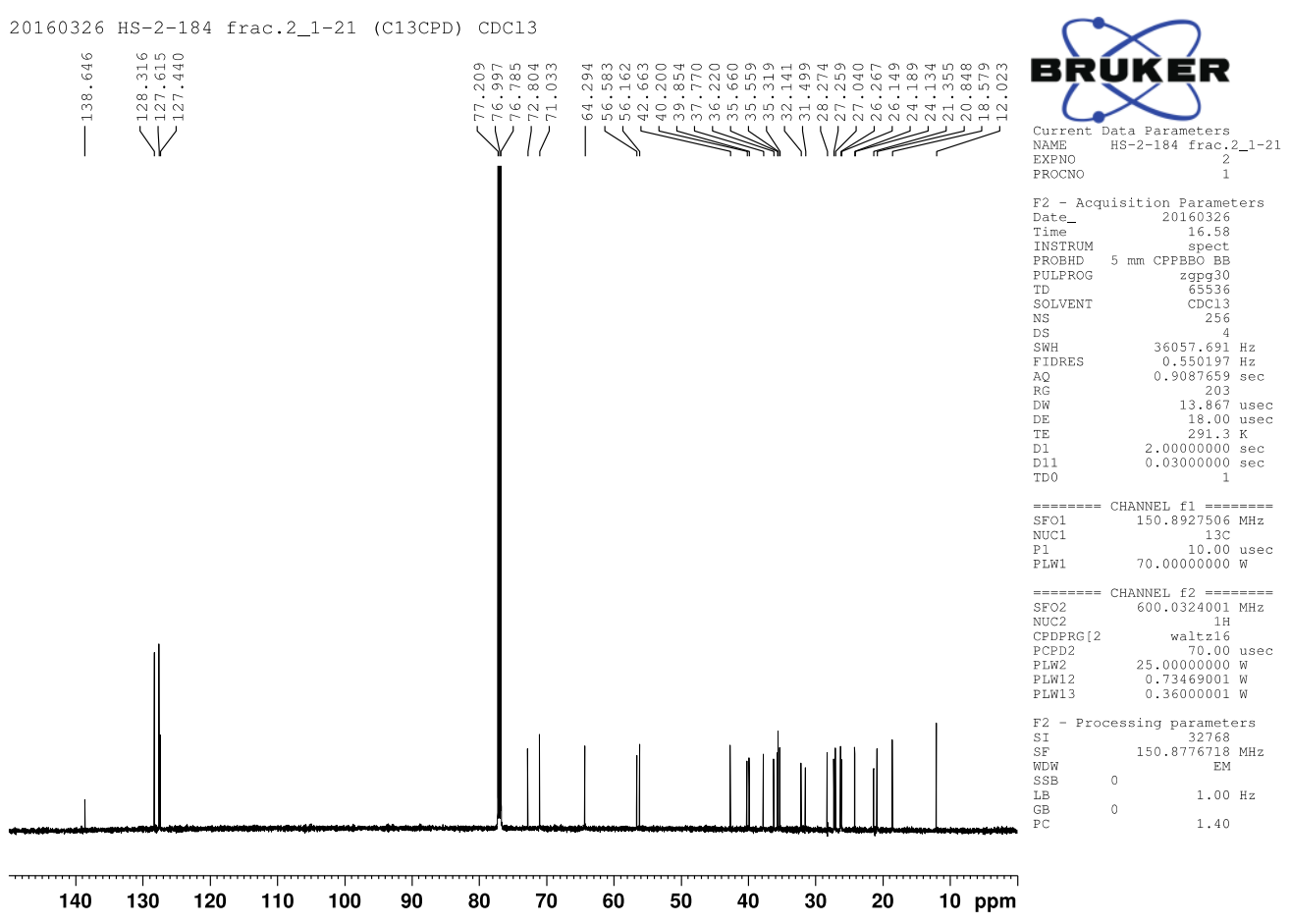


(xiv) compound 20a

${ }^{1} \mathrm{H}$ NMR

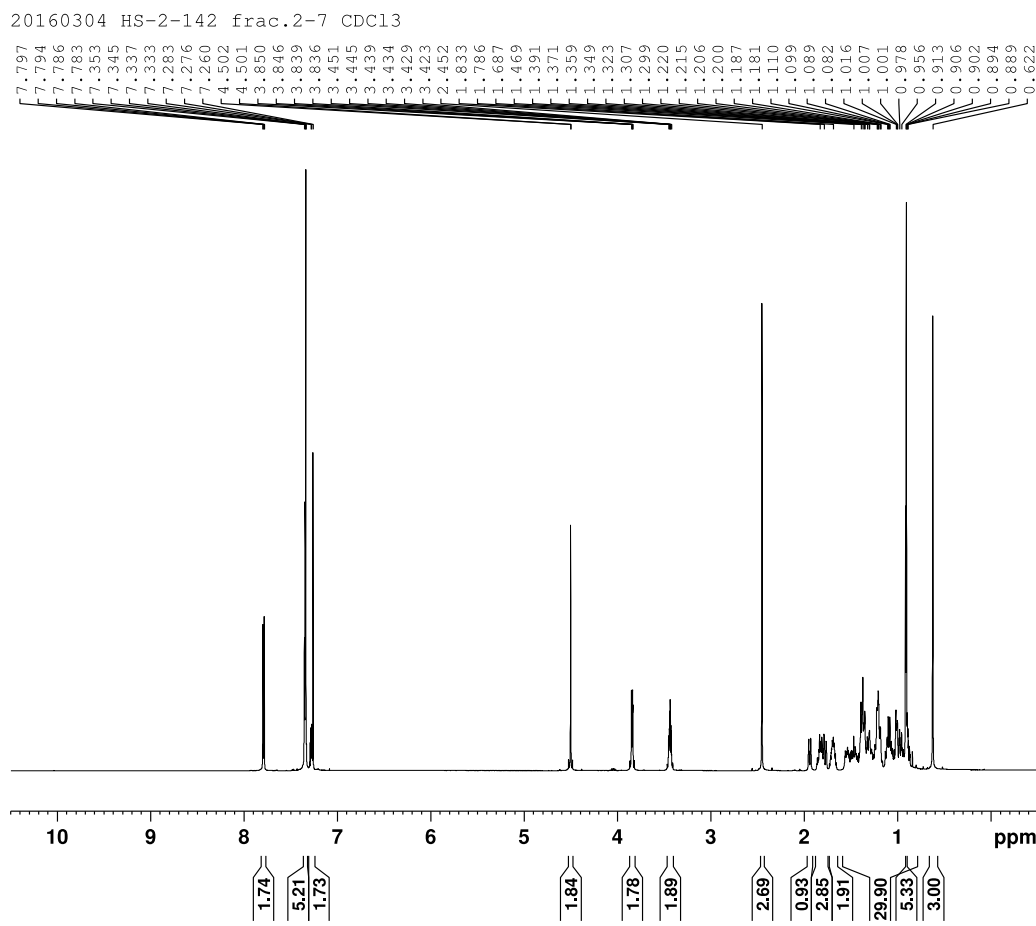

${ }^{13} \mathrm{C}$ NMR

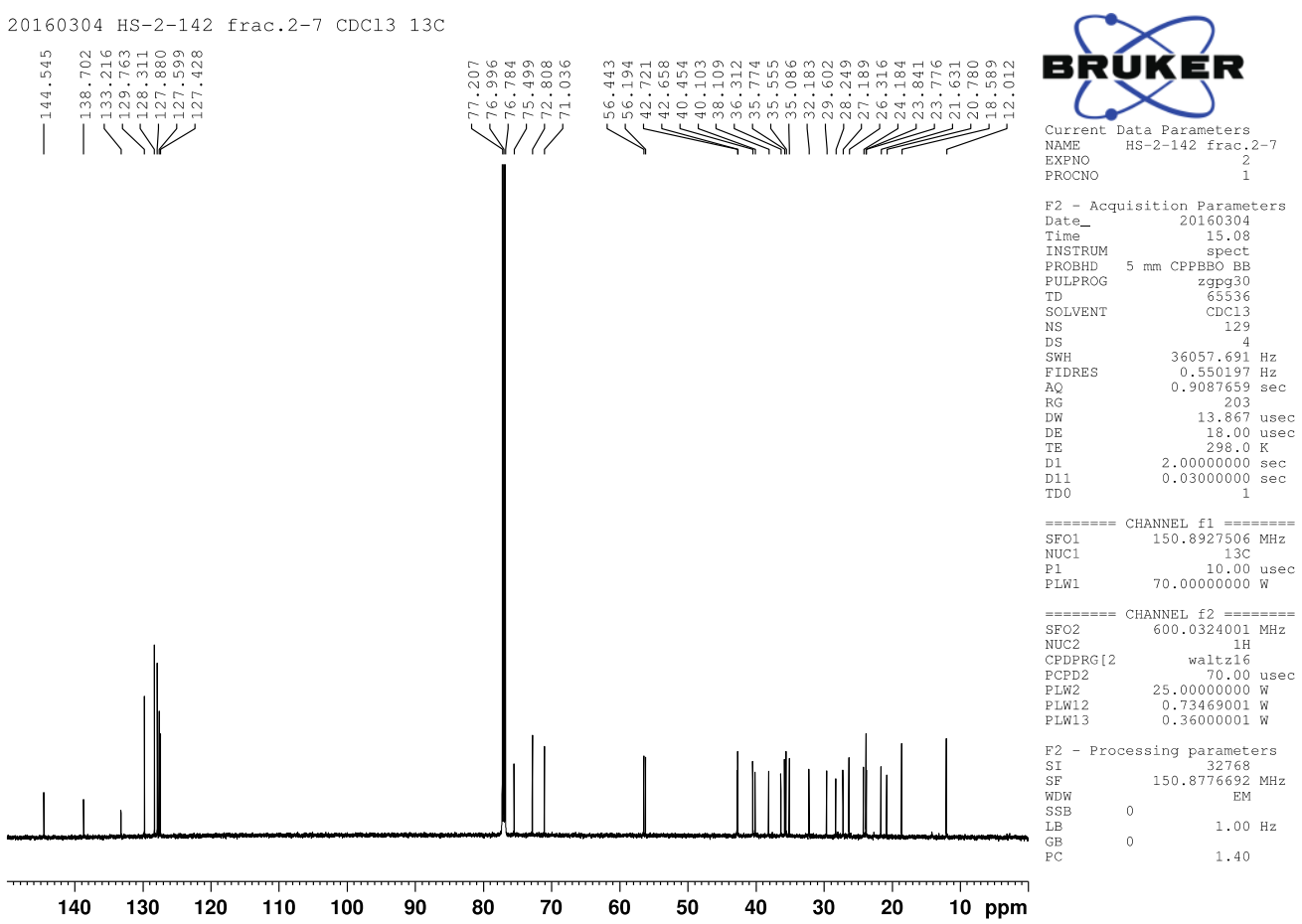


(xv) compound 20b

${ }^{1} \mathrm{H}$ NMR

20160326 HS-2-187 frac.5-15 CDC13

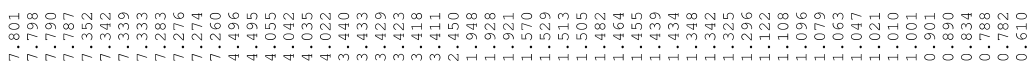
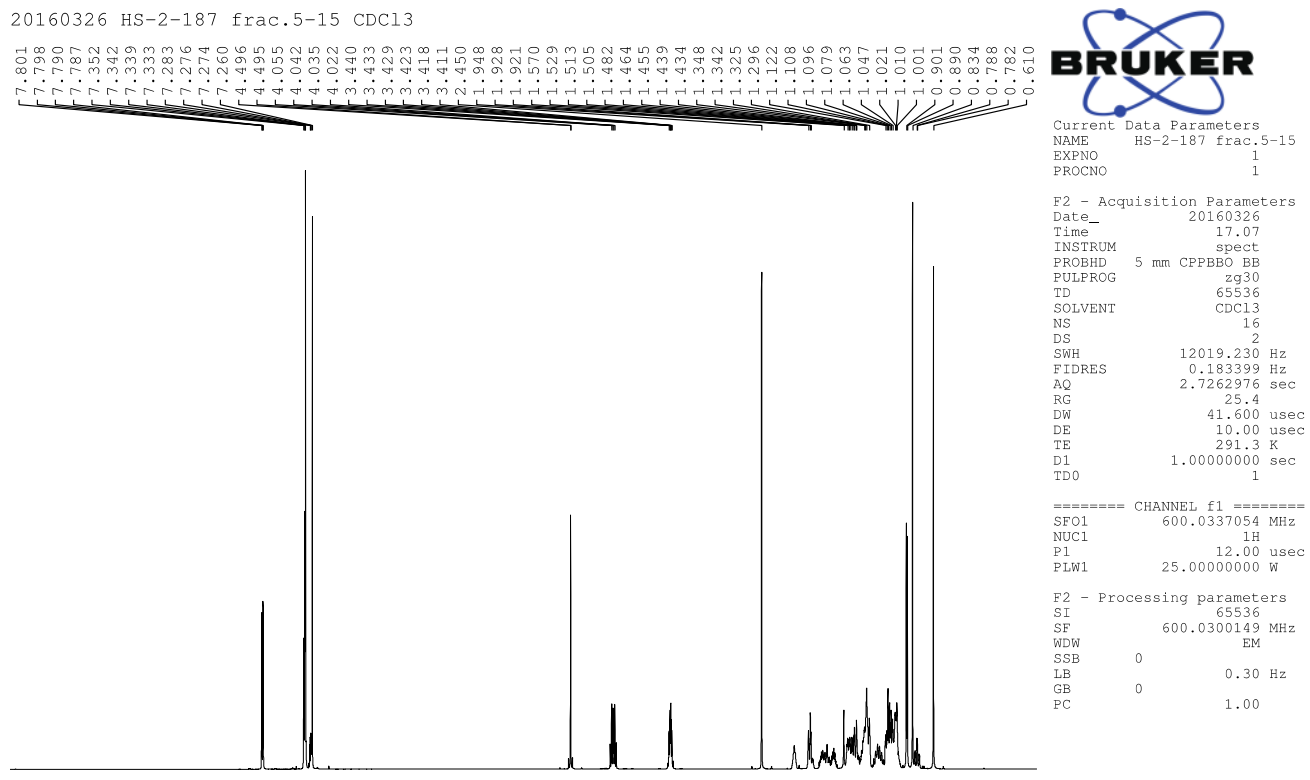

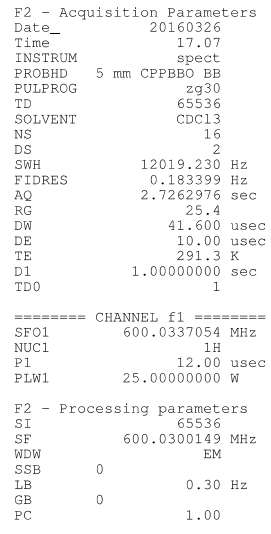

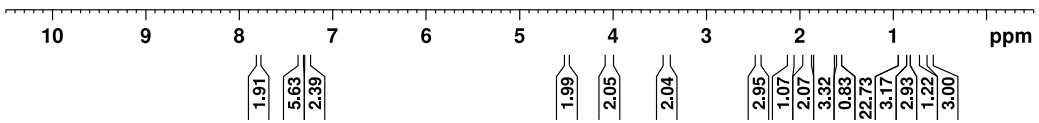

${ }^{13} \mathrm{C}$ NMR

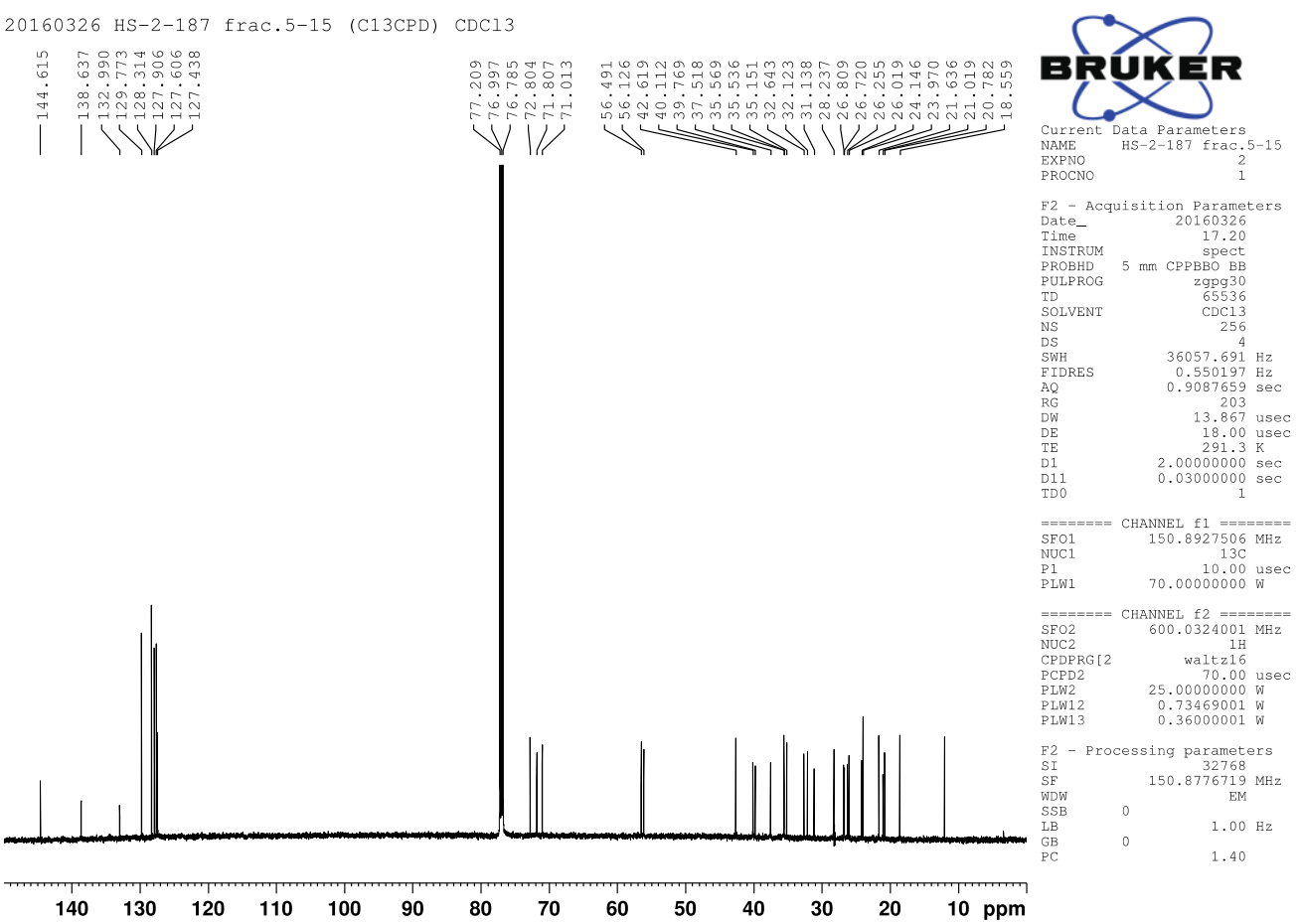


(xvi) compound 21a

${ }^{1} \mathrm{H}$ NMR

20160304 HS-2-146 frac.2_14-24 CDCl3

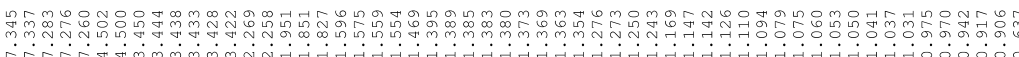
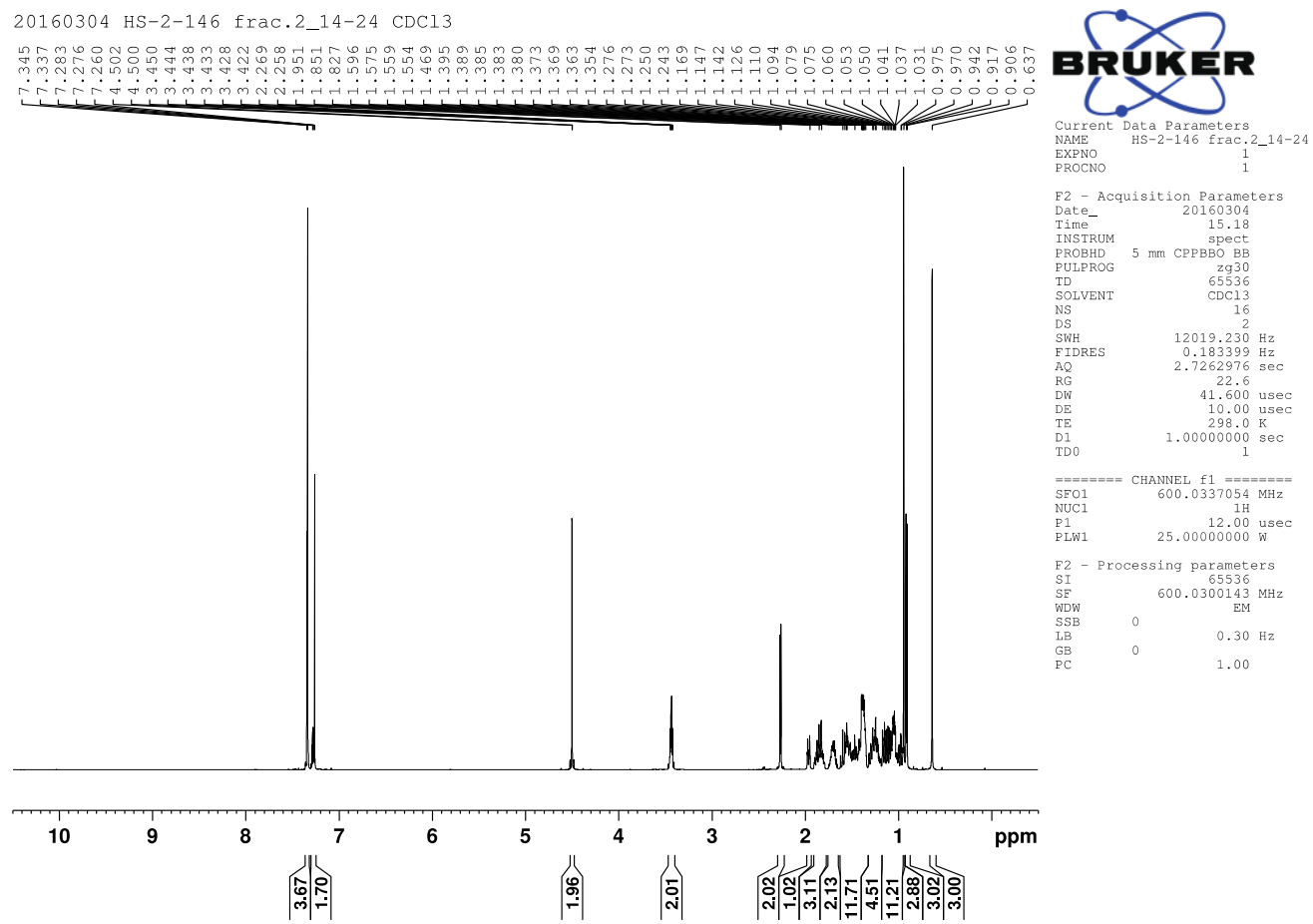

${ }^{13} \mathrm{C}$ NMR

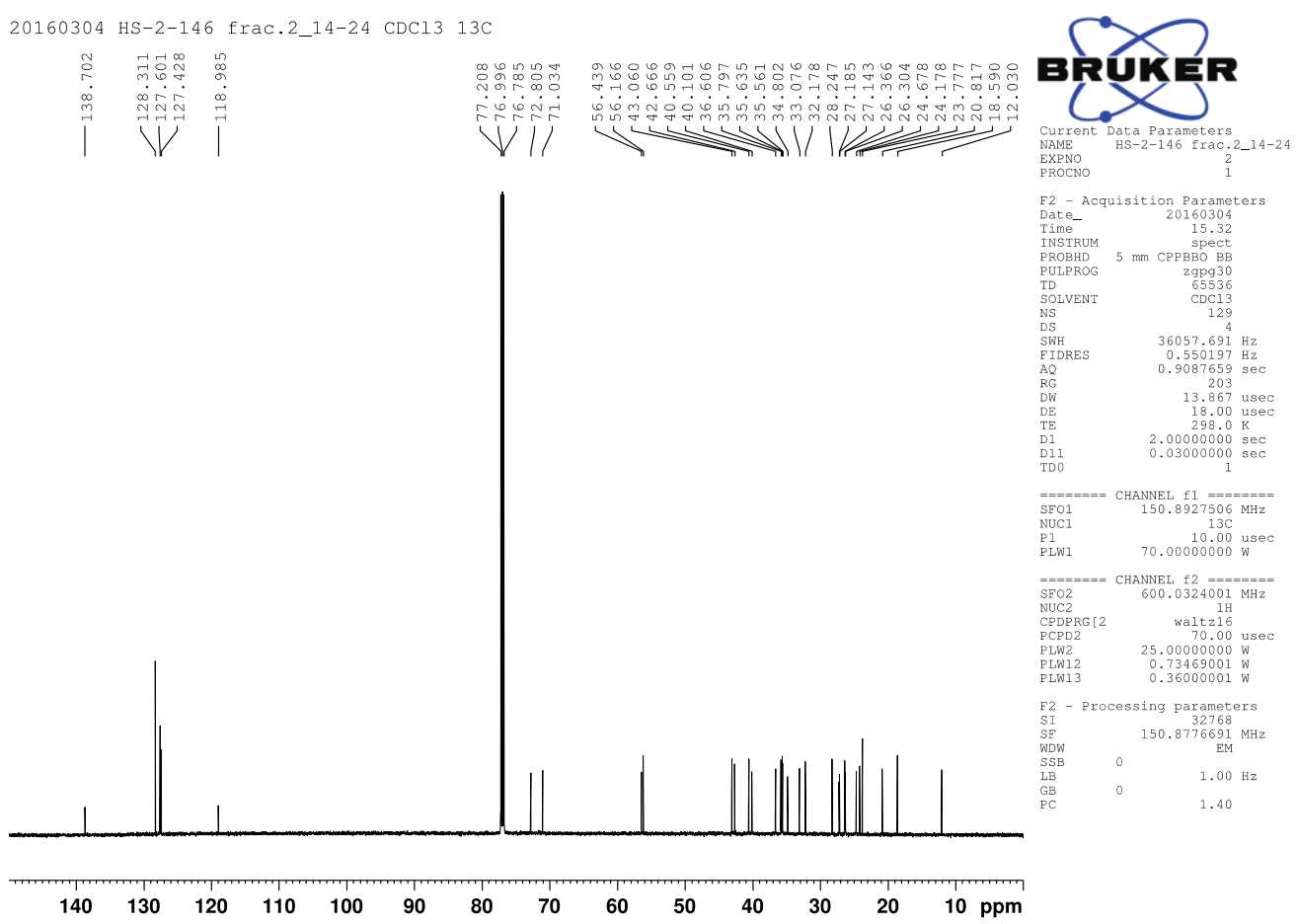


(xvii) compound 21b

${ }^{1} \mathrm{H}$ NMR

20160326 HS-2-191,194 GPC 2_2 CDC13

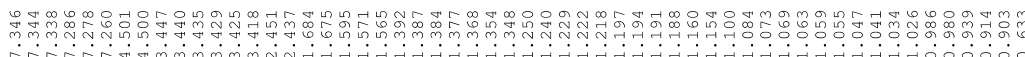
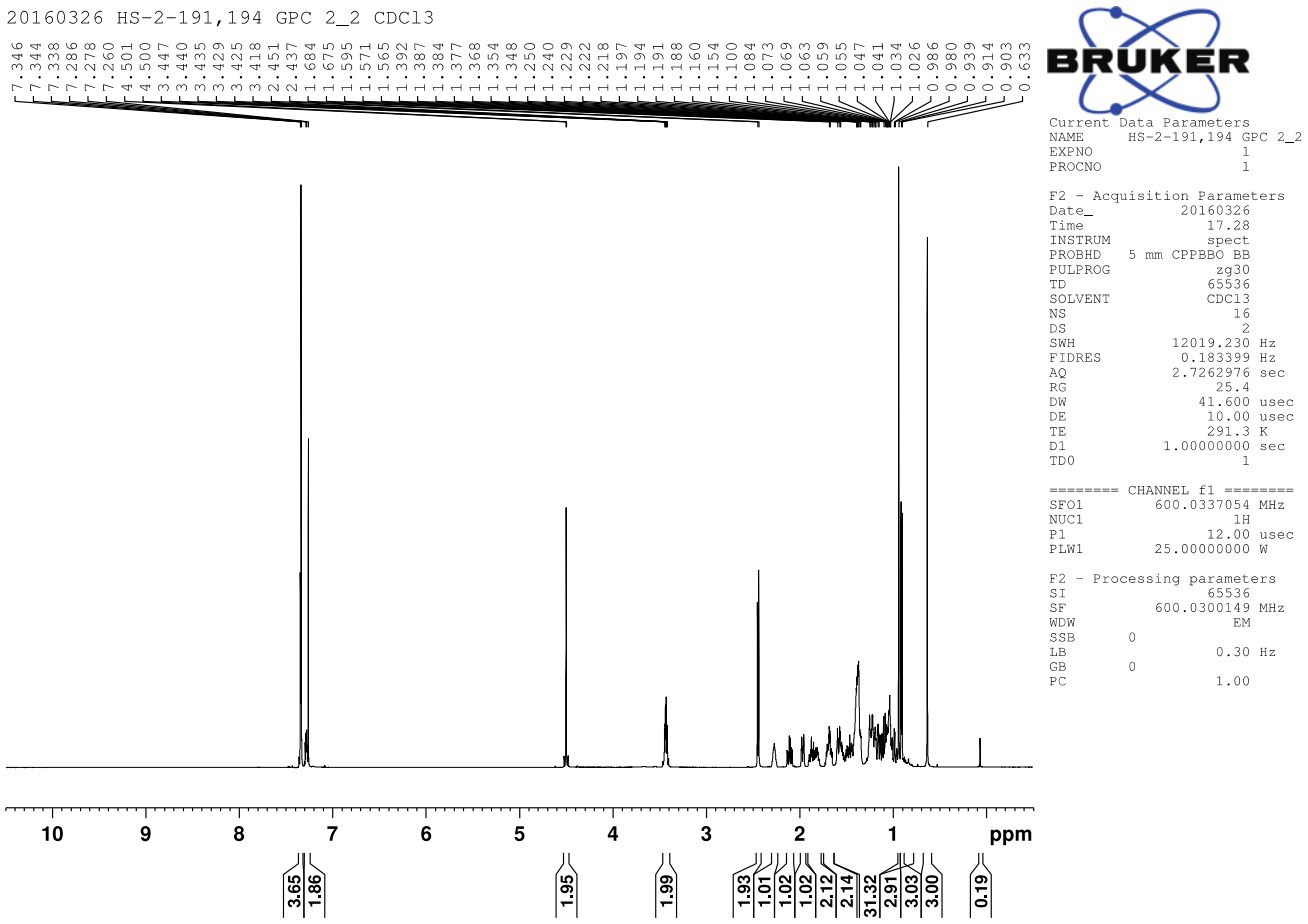

${ }^{13} \mathrm{C}$ NMR

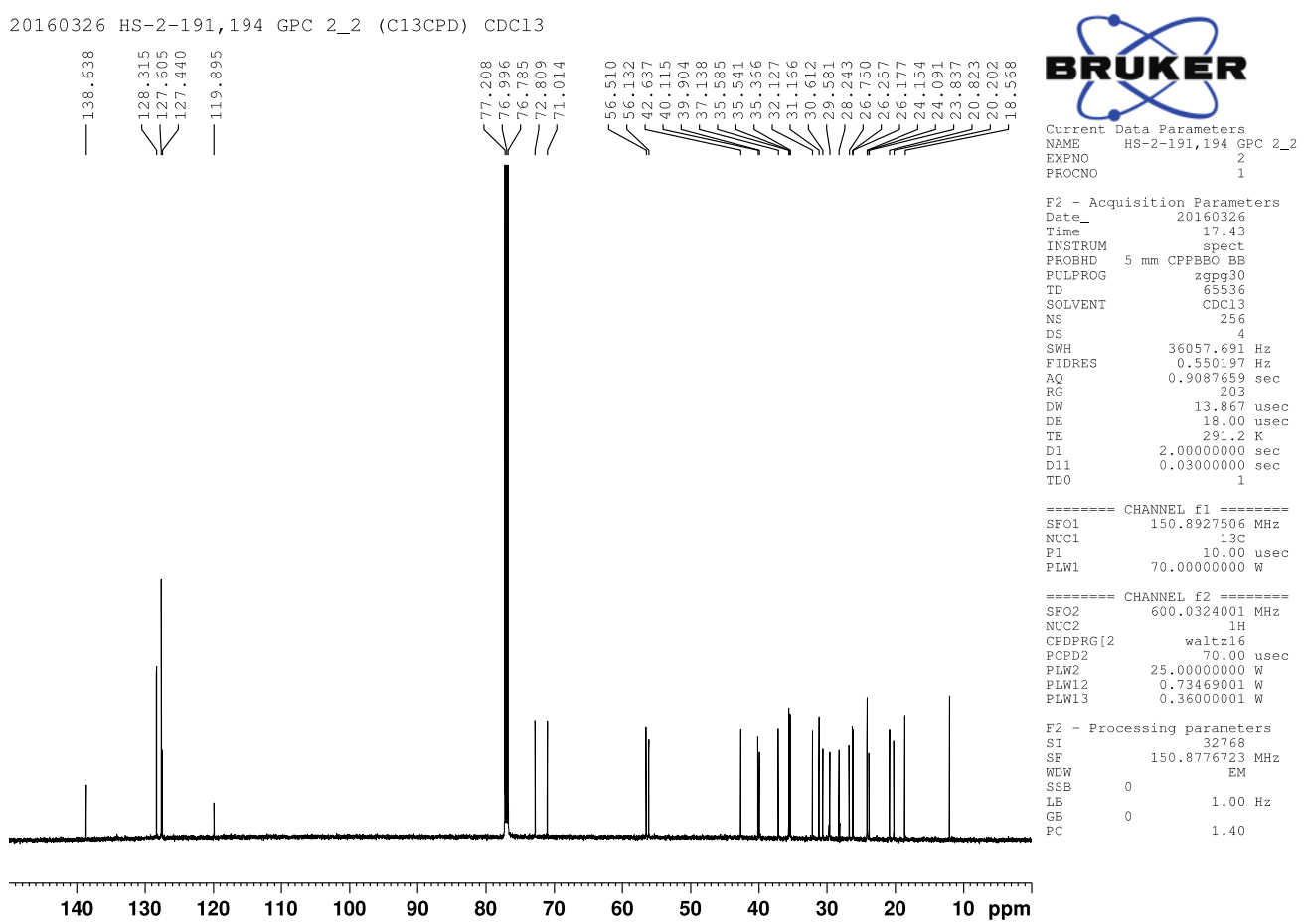


(xviii) compound 22a

${ }^{1} \mathrm{H}$ NMR

20160304 HS-2-146 frac. 6-12 CDC13

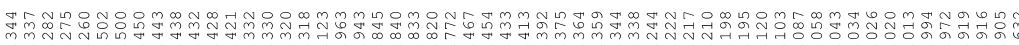
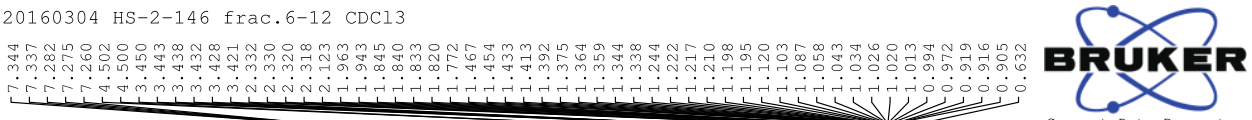

Current Data Parameters
NAME
EXPNO
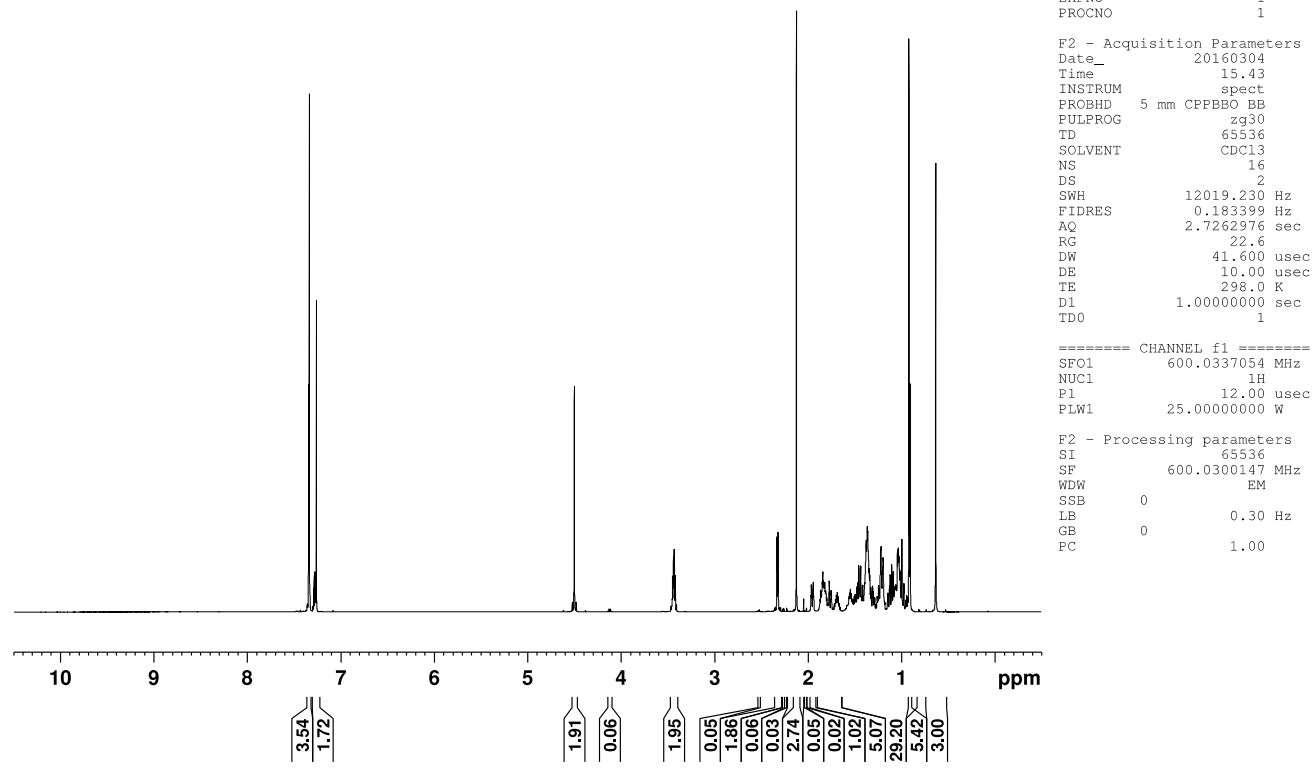

${ }^{13} \mathrm{C}$ NMR

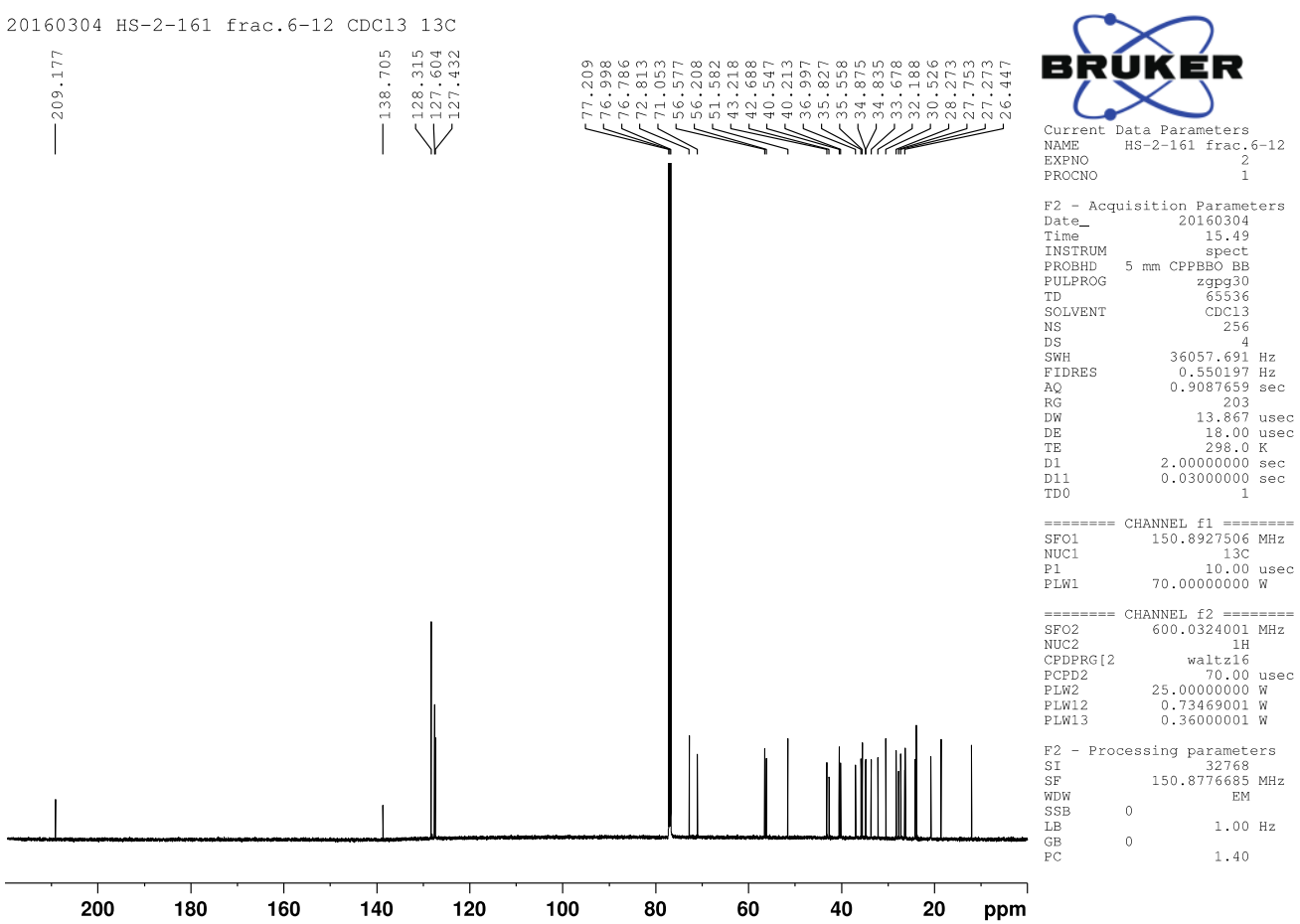


(xix) compound 22b

${ }^{1} \mathrm{H}$ NMR

20160326 HS-2-198 frac3-8 CDCl3

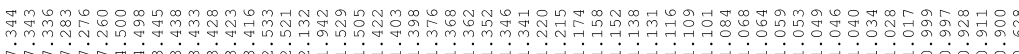
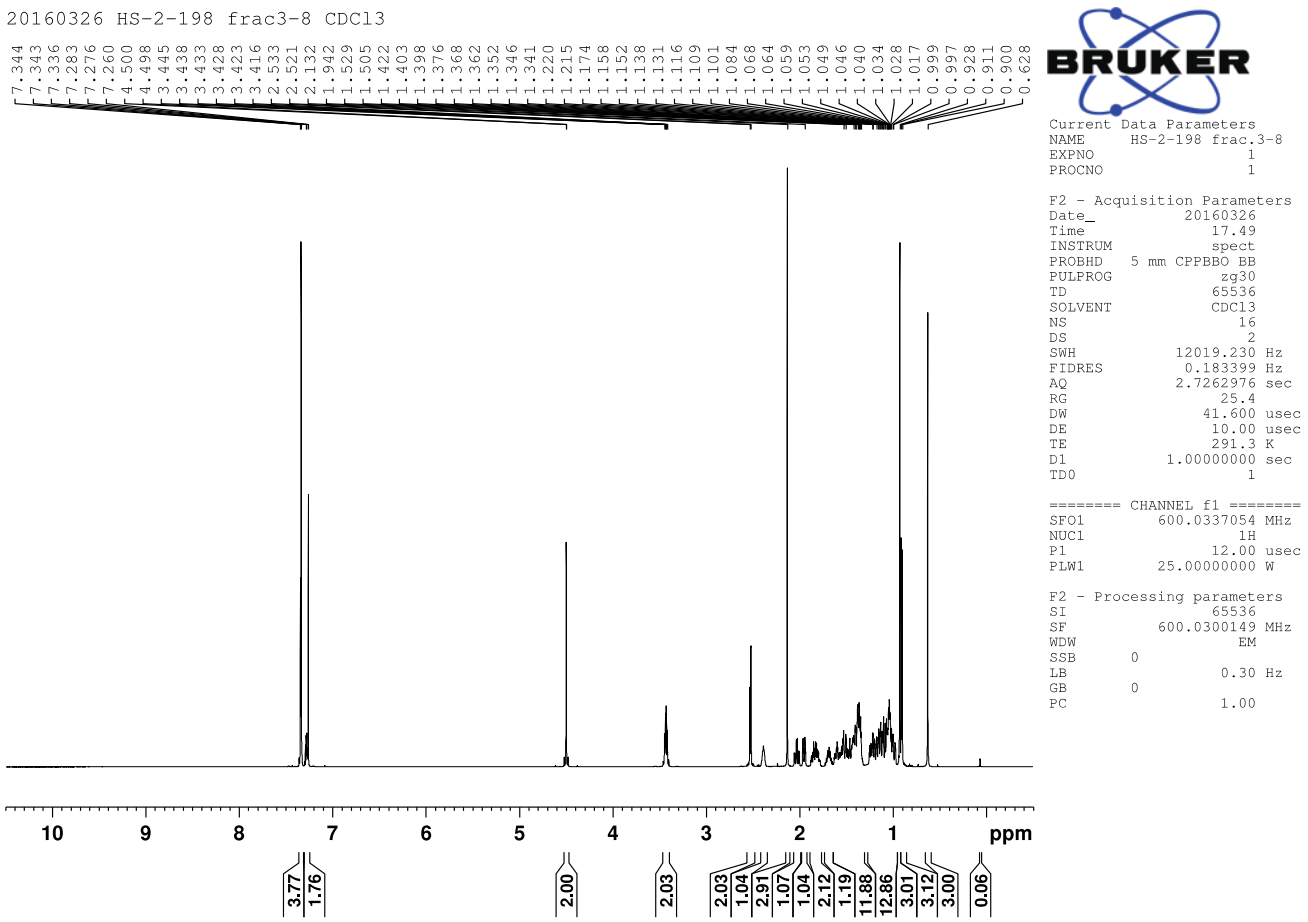

${ }^{13} \mathrm{C}$ NMR

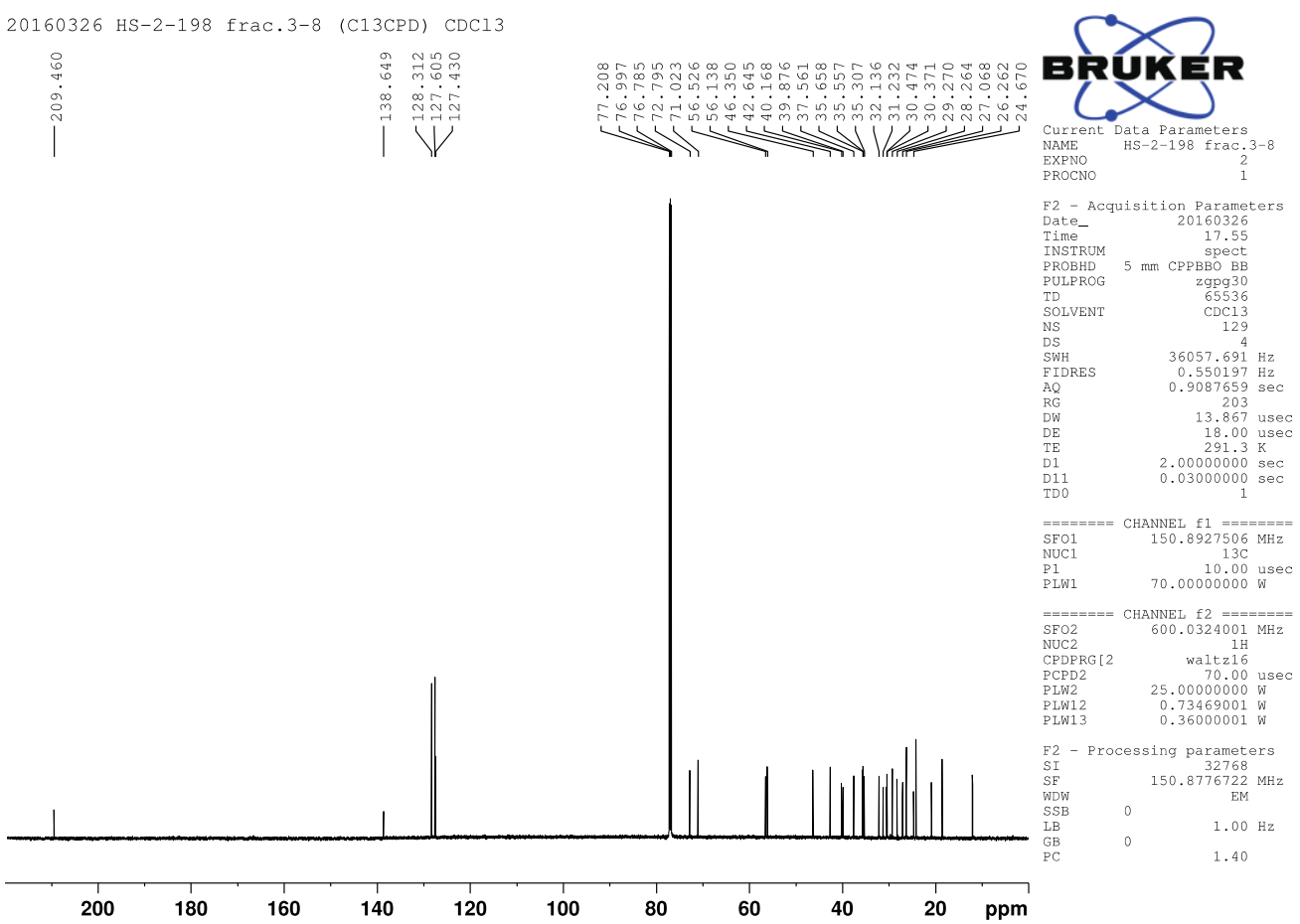


(xx) compound 23a

${ }^{1} \mathrm{H}$ NMR

20160304 HS-2-166 frac. $21-39 \mathrm{CDCl} 3$

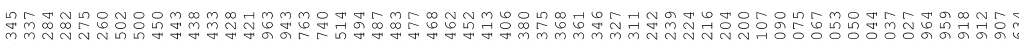
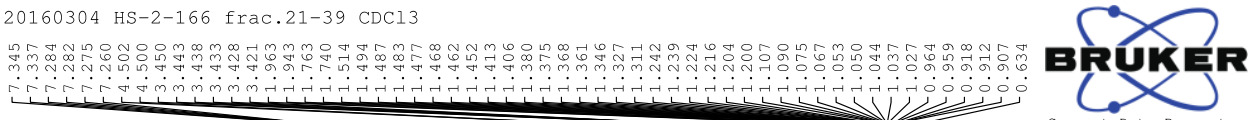

Current Data Parameters
NAME
EXPNO
PRS-2-156 frac
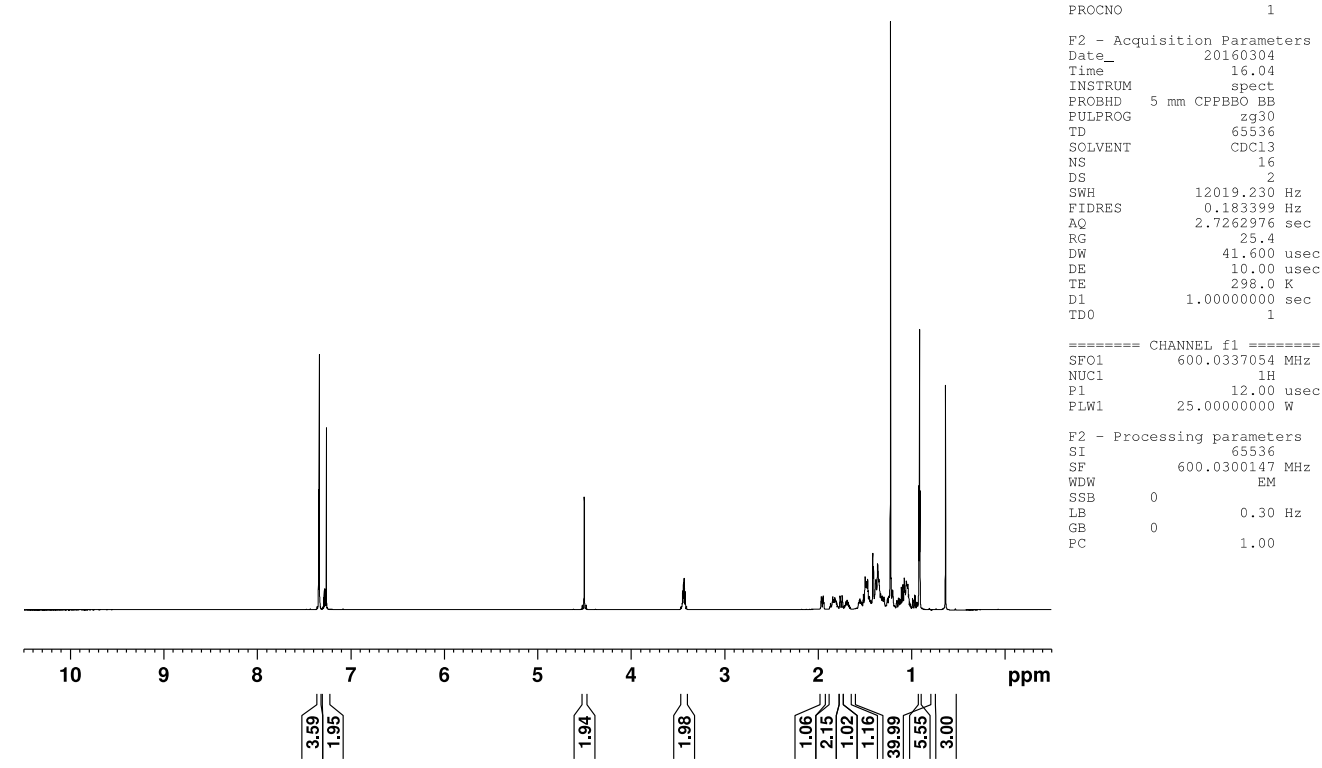

${ }^{13} \mathrm{C}$ NMR

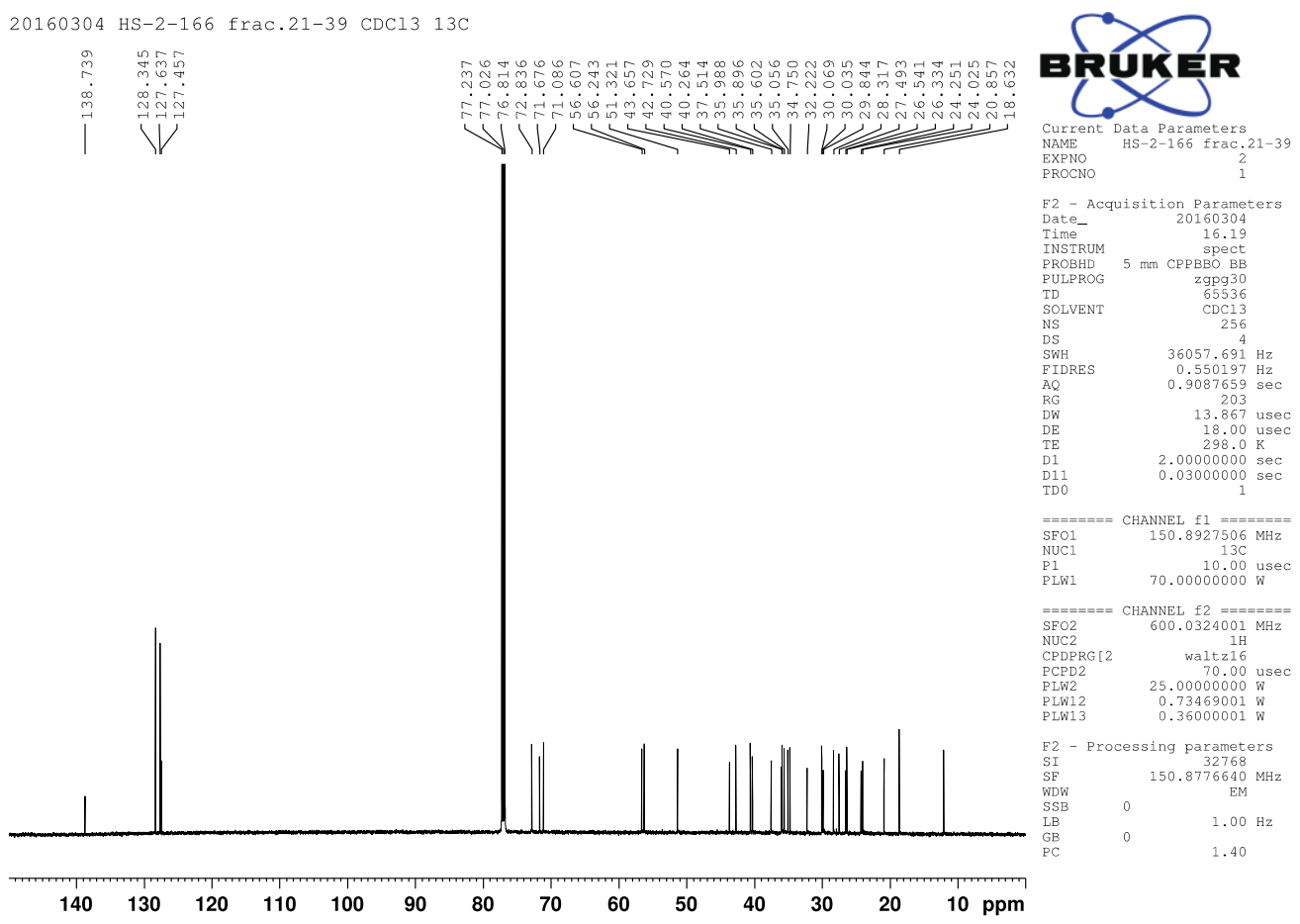


(xxi) compound 23b

${ }^{1} \mathrm{H}$ NMR

20160308 HS-3-006 frac. 8-22 CDC13

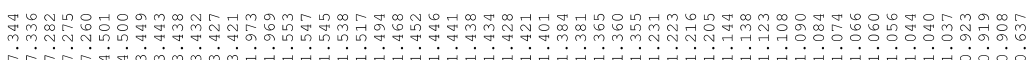
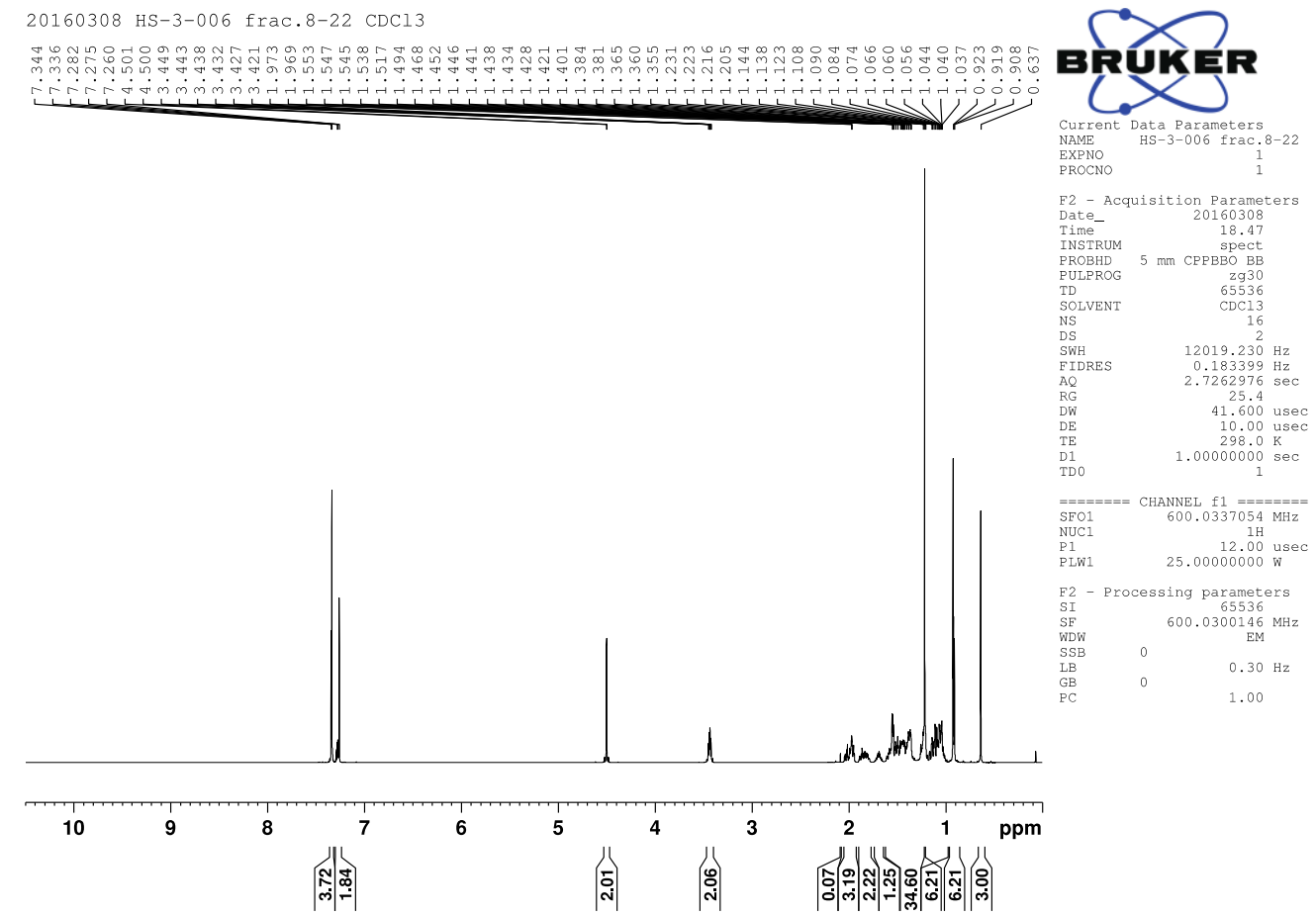

${ }^{13} \mathrm{C}$ NMR

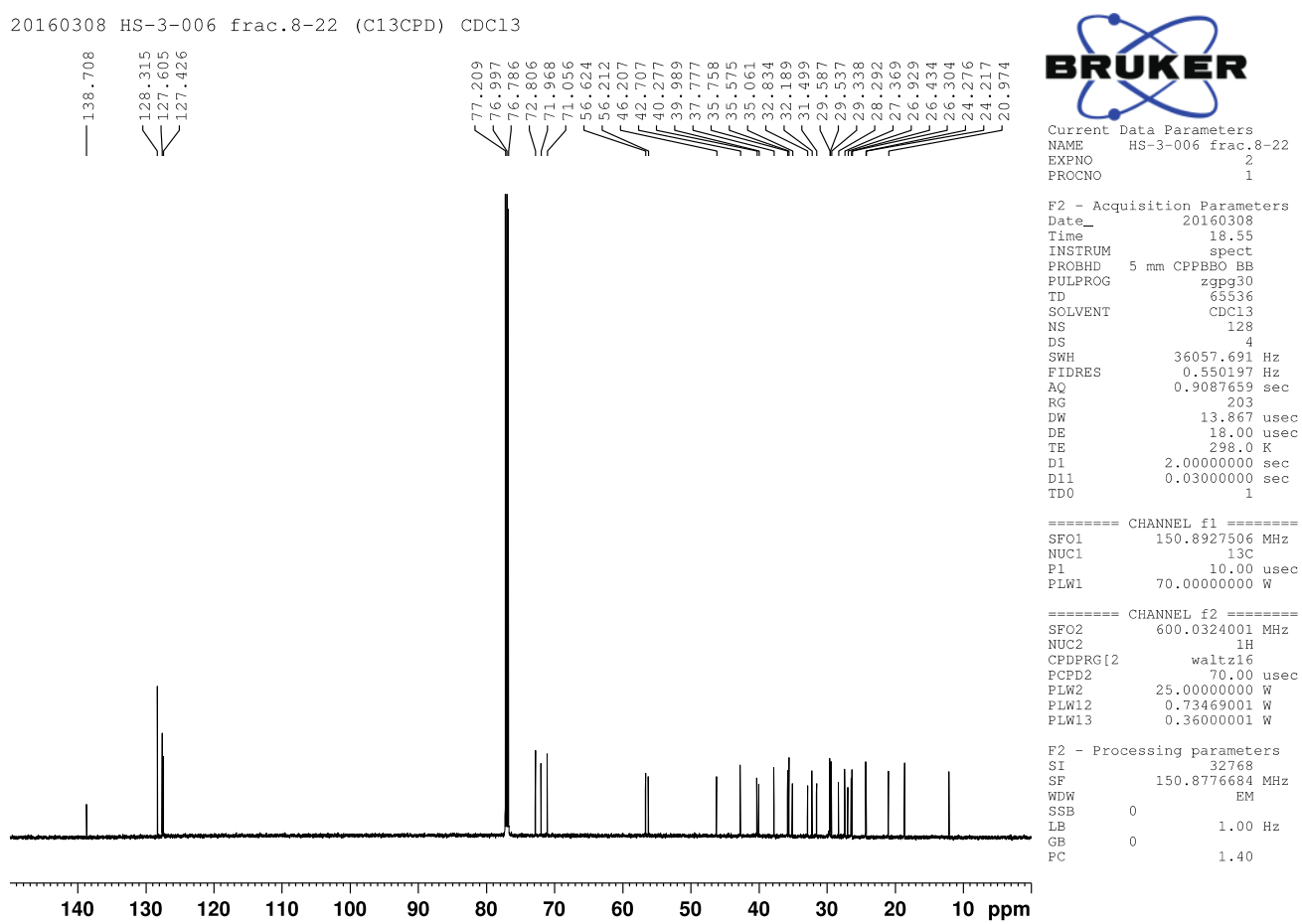


(xxii) compound 24a

${ }^{1} \mathrm{H}$ NMR
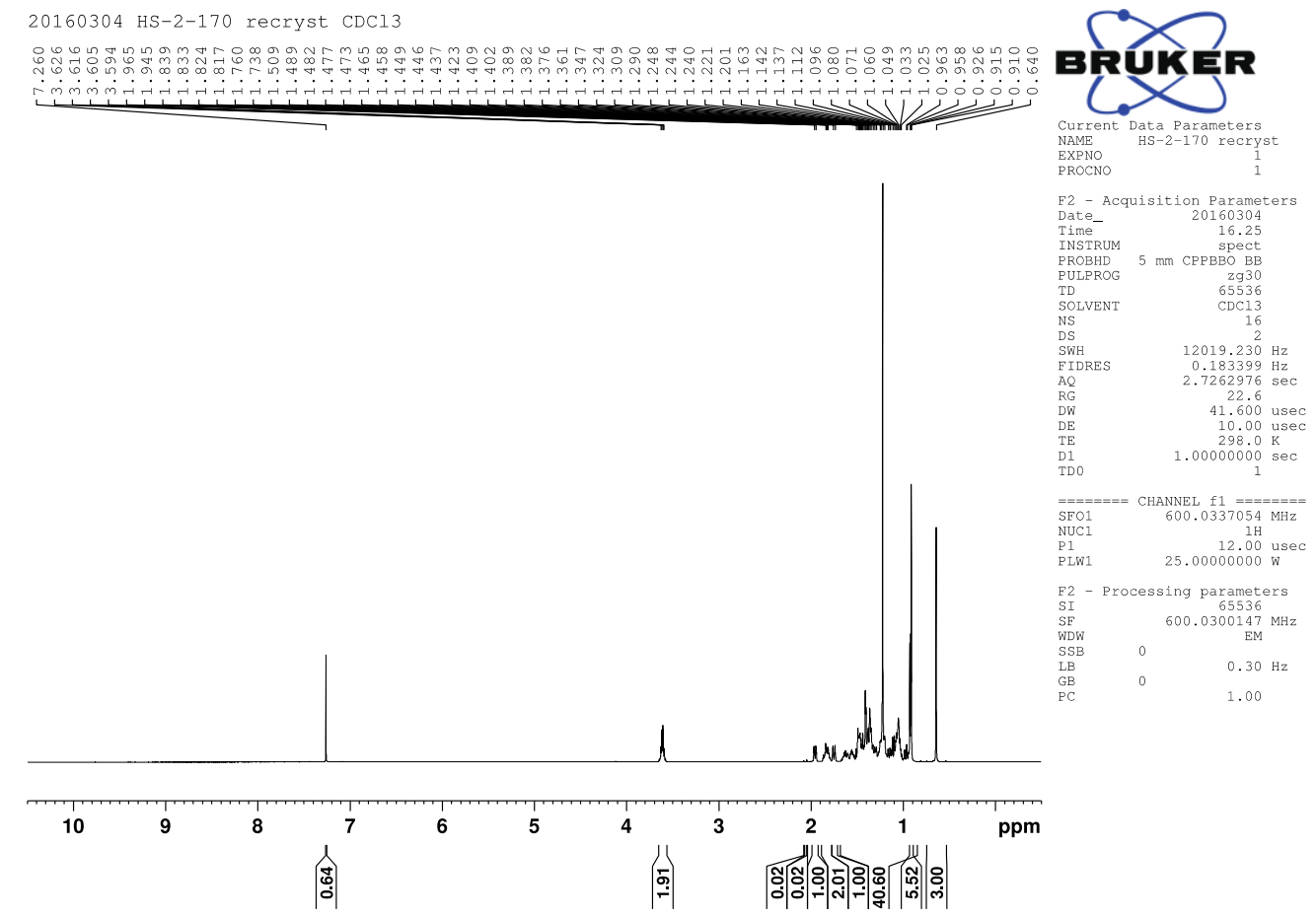

${ }^{13} \mathrm{C}$ NMR

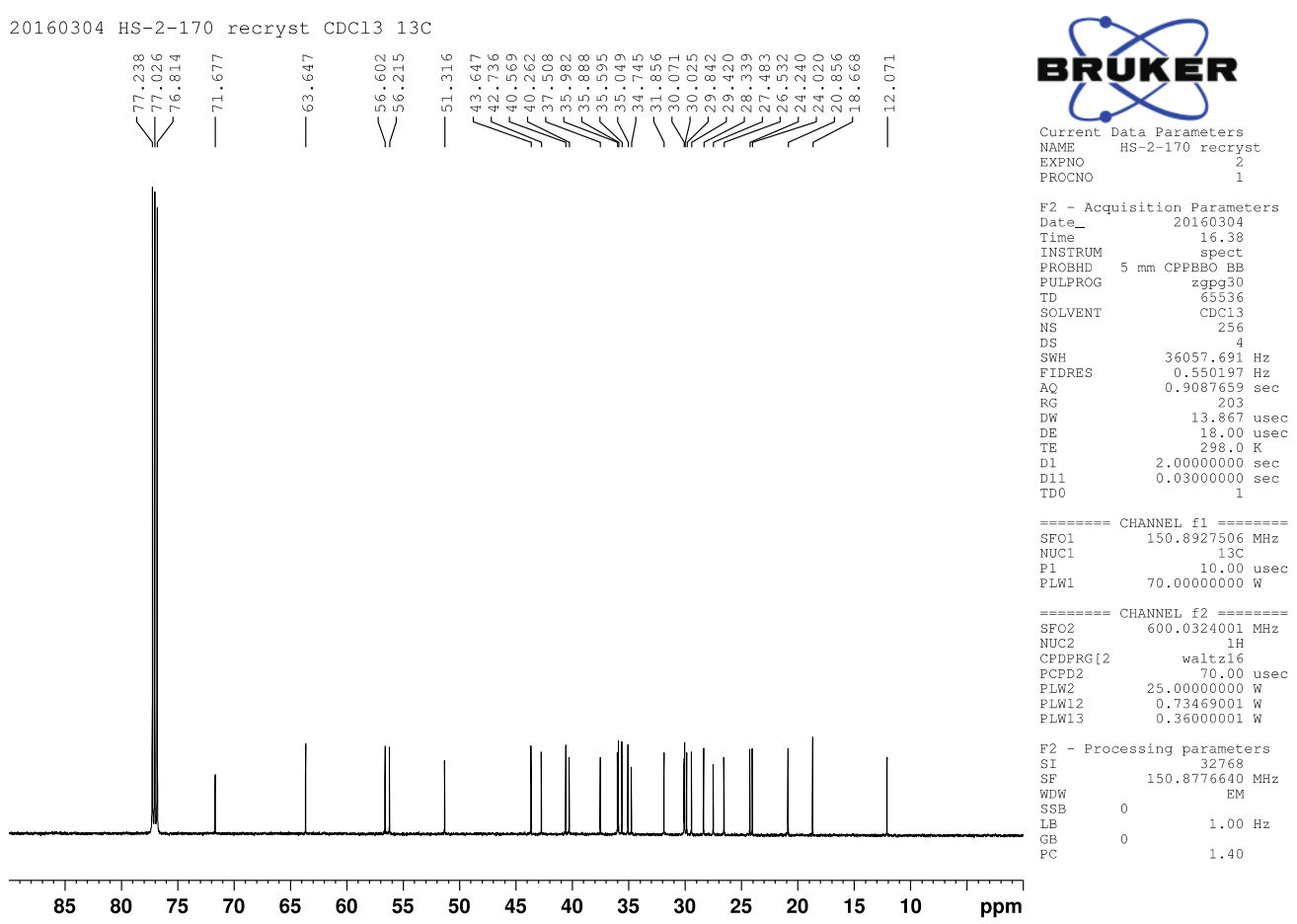


(xxiii) compound 24b

${ }^{1} \mathrm{H}$ NMR
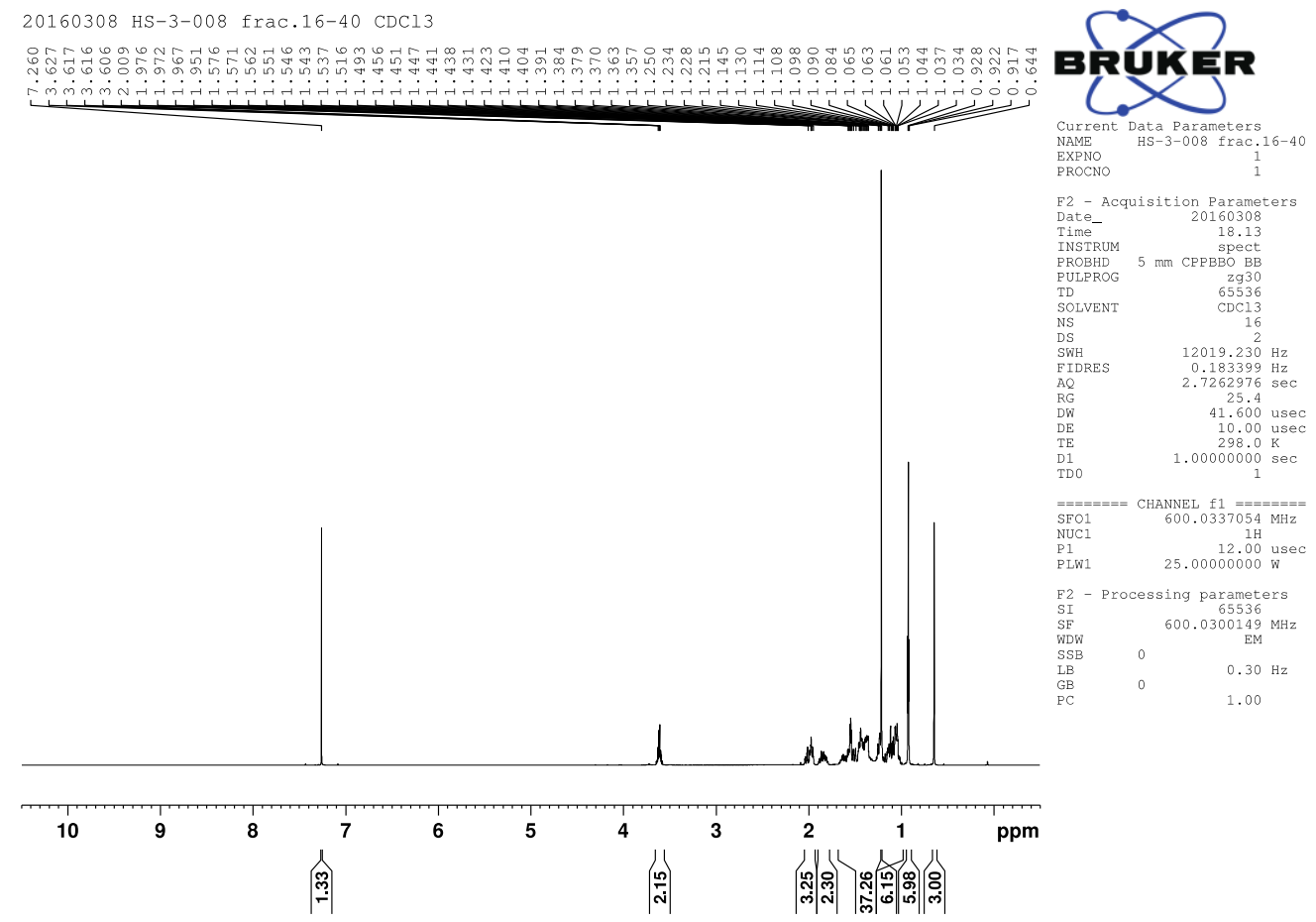

${ }^{13} \mathrm{C}$ NMR

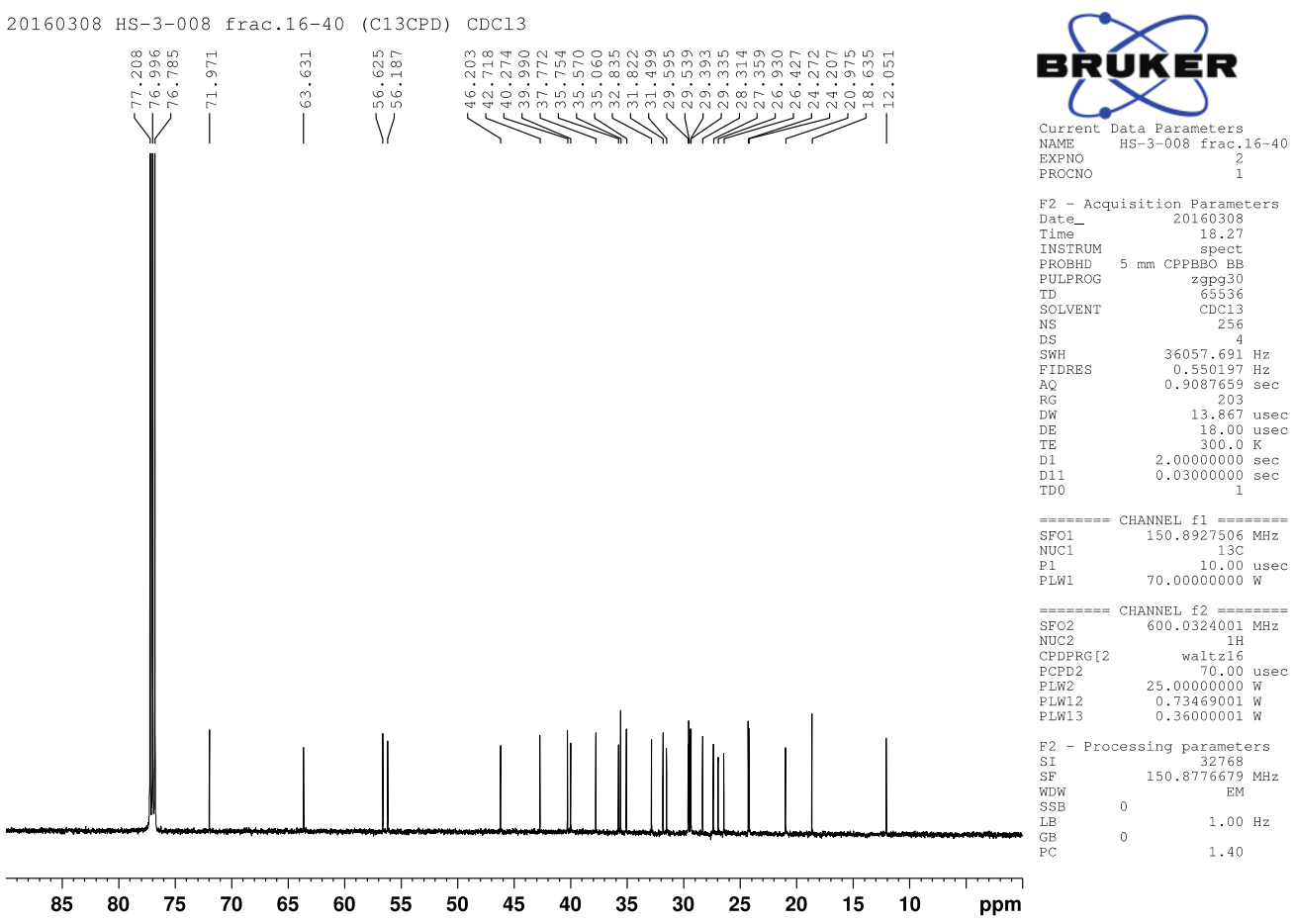


(xxiv) compound 6

${ }^{1} \mathrm{H}$ NMR

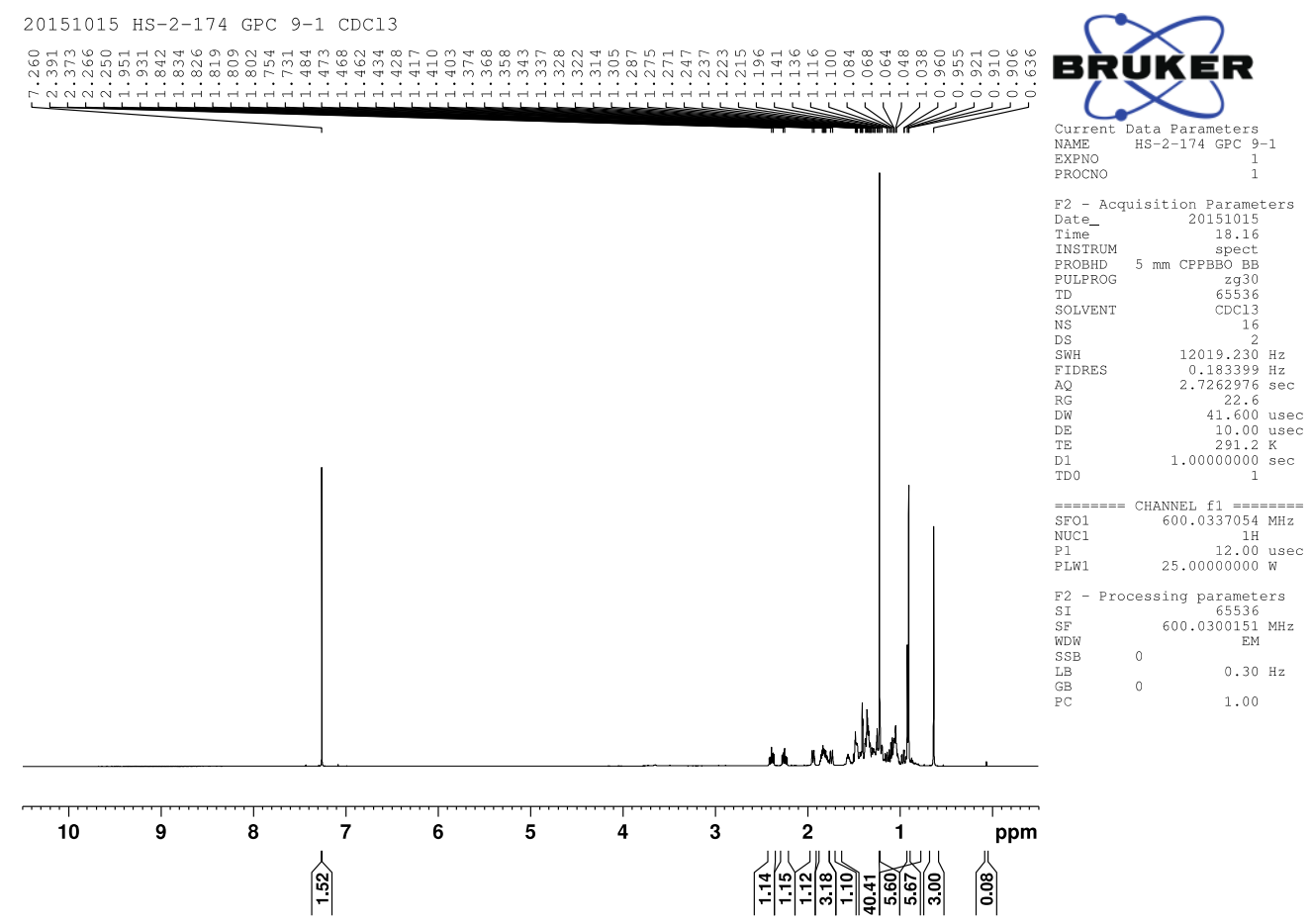

${ }^{13} \mathrm{C}$ NMR

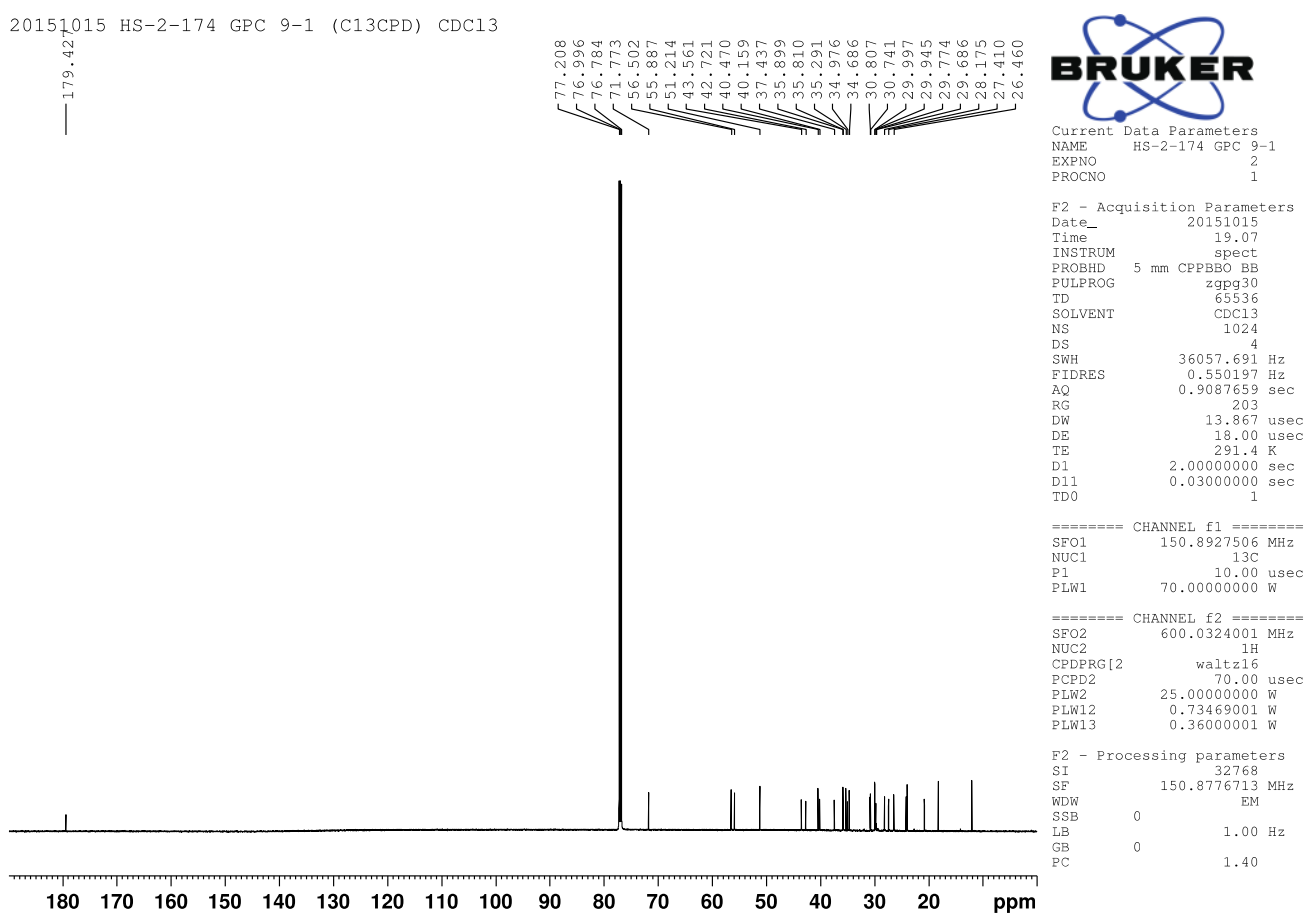


(xxv) compound 7

${ }^{1} \mathrm{H}$ NMR

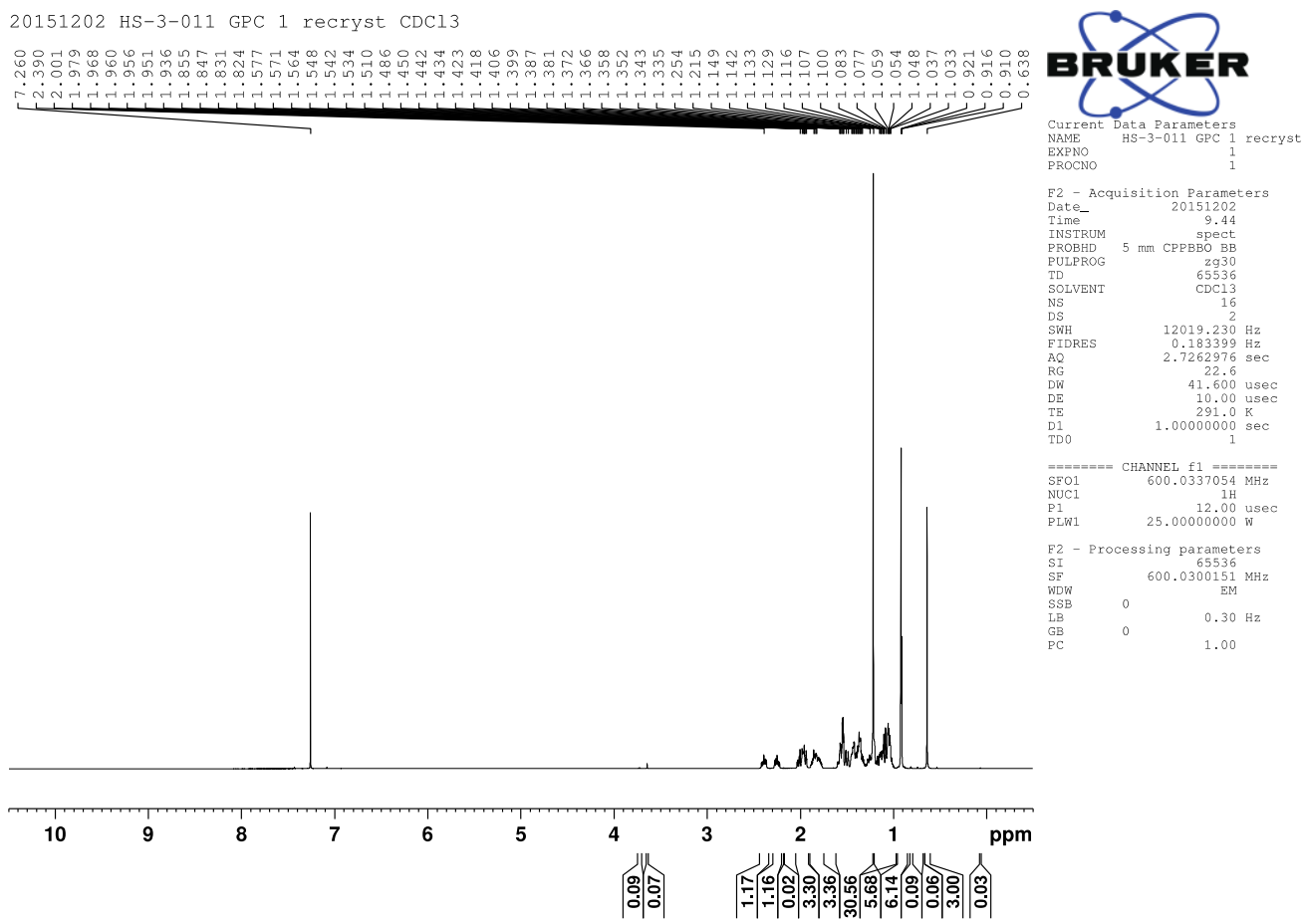

${ }^{13} \mathrm{C}$ NMR

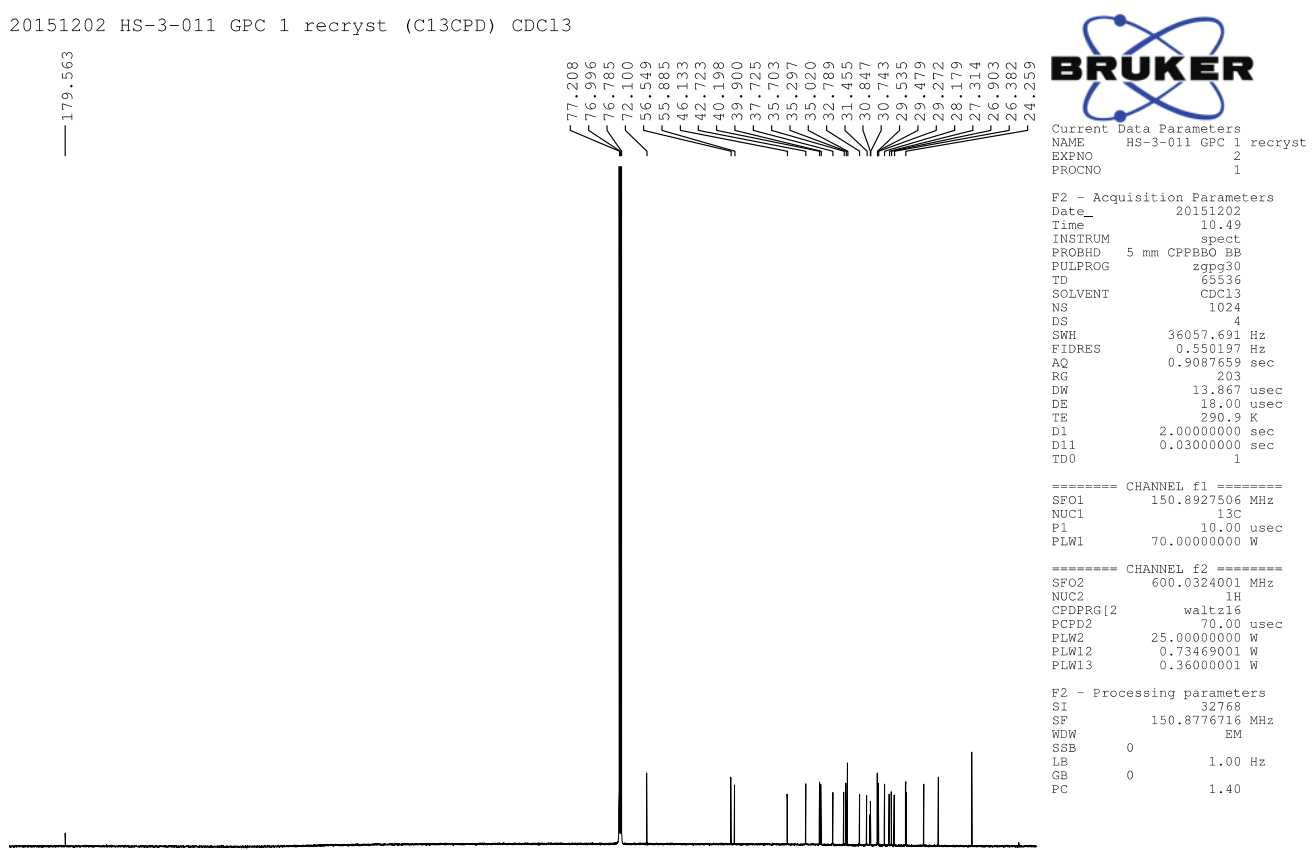

$\begin{array}{llllllllllllllllll}180 & 170 & 160 & 150 & 140 & 130 & 120 & 110 & 100 & 90 & 80 & 70 & 60 & 50 & 40 & 30 & 20 & \mathrm{ppm}\end{array}$ 